\title{
3-D AND QUASI-2-D DisCRETE ELEMENT MODELING OF GRAIN COMMINGLING IN A BUCKET ELEVATOR BOOT SYSTEM
}

\author{
J. M. Boac, M. E. Casada, R. G. Maghirang, J. P. Harner III
}

\begin{abstract}
Unwanted grain commingling impedes new quality-based grain handling systems and has proven to be an expensive and time-consuming issue to study experimentally. Experimentally validated models may reduce the time and expense of studying grain commingling while providing additional insight into details of the particle flow. In this study, grain commingling in a pilot-scale bucket elevator boot was first modeled in three-dimensional (3-D) discrete element method (DEM) simulations. Experiments on the pilot-scale boot were performed using red-dyed and clear (uncolored) soybeans to validate the 3-D DEM model. Predicted results from the 3-D boot model generally followed the experimental data but tended to underpredict commingling early in the process. To reduce computational time, quasi-two-dimensional (quasi-2-D) DEM simulations were also evaluated. Comparison of predicted average commingling of five quasi-2-D boot models with reduced control volumes (i.e., with boot widths from four to seven times the mean particle diameter) led to the selection of the quasi-2-D model with a boot width of 5.6 times the mean particle diameter (i.e., 5.6d) to reduce computational time. In addition, the 3-D and quasi-2-D (5.6d) models were refined by accounting for the initial surge of particles at the beginning of each test and correcting for the effective dynamic gap between the bucket cups and the boot wall. The quasi-2-D (5.6d) models reduced simulation run time by approximately 70\% compared to the 3-D model of the pilot-scale boot. Results of this study can be used to accurately predict commingling levels and improve grain handling, which can help farmers and grain handlers reduce costs and maintain grain purity during transport and export of grain.
\end{abstract}

Keywords. Bucket elevator boot, Discrete element method, Grain commingling, Soybeans, Three-dimensional and quasitwo-dimensional simulations.

I dentity preservation programs are aimed at maintaining the genetic and physical purity of grain. Segregation of grain with specific attributes has been increasing in the grain industry in recent years and is anticipated to grow. The introduction of genetically modified (also called transgenic or biotech) crops for feed, pharmaceutical, and industrial uses into the U.S. grain handling system has shown that the infrastructure is often unable to identity-preserve the grains to the desired level of purity (Ingles et al., 2006). This was exemplified by the incidents

Submitted for review in September 2011 as manuscript number FPE 9405; approved for publication by the Food \& Process Engineering Institute of ASABE in February 2012. Presented at the 2010 ASABE Annual Meeting as Paper No. 1009152.

Mention of trade names or commercial products in this article is solely for the purpose of providing specific information and does not imply recommendation or endorsement by the USDA. The USDA is an equal opportunity provider and employer.

The authors are Josephine M. Boac, ASABE Member, Research Associate, Department of Biological and Agricultural Engineering, Kansas State University, Manhattan, Kansas; Mark E. Casada, ASABE Member, Research Agricultural Engineer, USDA-ARS Center for Grain and Animal Health Research (CGAHR), Engineering and Wind Erosion Research Unit (EWERU), Manhattan, Kansas; and Ronaldo G. Maghirang, ASABE Member, Professor, and Joseph P. Harner III, ASABE Member, Professor and Department Head, Department of Biological and Agricultural Engineering, Kansas State University, Manhattan, Kansas. Corresponding author: Mark E. Casada, USDAARS Center for Grain and Animal Health Research (CGAHR), Engineering and Wind Erosion Research Unit (EWERU), 1515 College Ave., Manhattan, KS 66502; phone: 785-776-2758; e-mail: casada@ ksu.edu. of Starlink corn (Bucchini and Goldman, 2002) and GT200-containing canola seed (Kilman and Carroll, 2002).

For this article, grain commingling is defined as unintentional introduction of other grains that serve as impurities, which directly reduce the level of purity in grain entering an elevator facility. There are three approaches for addressing commingling during grain handling: (1) ignore it, (2) containerize the identity-preserved grain or handle it only in dedicated facilities and transportation equipment, or (3) segregate the identity-preserved grain in non-dedicated facilities. The first two methods are the most common, and the latter method has limited scientific data for evaluating its effectiveness. The latter method is the subject of this study.

In addition to unintentional and natural threats to grain purity, intentional introduction of contaminants is also possible. The Strategic Partnership Program Agroterrorism (SPPA) initiative listed grain elevator and storage facilities as sites that are critical nodes for assessment because of their vulnerability to terrorist attack with biological weapons (USFDA, 2006).

For both intentional and unintentional commingling, previous research in grain elevators (Ingles, et al., 2003, 2006) and with farm equipment (Greenlees and Shouse, 2000; Hirai et al., 2006; Hanna et al., 2006) showed large variation in grain commingling between and within facilities. These large variations can greatly increase the number of experiments necessary to make widely applicable inferences. However, the inference space can also be greatly 
increased by using theoretical modeling, generally known as mechanistic modeling, to add extensive information from established laws of motion. A mechanistic model of grain movement in the bucket elevator leg could enhance prediction capabilities for grain commingling.

Both continuum models and the discrete element method (DEM) have been used to model the motion of particles (Wightman et al., 1998). Due to its ability to track individual particles, DEM can simulate discrete objects such as grain kernels and predict their movement and commingling in bucket elevator equipment. Previous simulations with DEM have involved two-dimensional (2-D) (Fillot et al., 2004; Fazekas et al., 2005; Sykut et al., 2008), threedimensional (3-D) (Hart et al., 1988; Sudah et al., 2005; Goda and Ebert, 2005; Takeuchi et al., 2008), and quasi-2D (Kawaguchi et al., 2000; Samadani and Kudrolli, 2001; Li et al., 2005; Kamrin et al., 2007; Ketterhagen et al., 2008) models, depending on the type of application. Quasi2-D (sometimes referred to as quasi-3-D) modeling uses a 2-D system but with added depth or width, usually equivalent to a small number of particle diameters (usually less than ten). A quasi-2-D model can be preferable to a 3-D model because it reduces computational time while maintaining the accuracy of the computations by capturing the 3-D effects of interacting spheres, unlike a 2-D model (Boac et al., 2010).

The objectives of this study were to: (1) simulate grain commingling in a pilot-scale boot using DEM models and evaluate the tradeoffs of computational speed versus accuracy for 3-D and quasi-2-D boot models, and (2) validate the models using soybeans as the test grain.

\section{Discrete Element Method}

DEM is a numerical modeling technique that simulates the dynamic motion and mechanical interaction of each particle using Newton's second law of motion and the force-displacement law. It was first introduced by Cundall (1971) and Cundall and Strack (1979) to model soil and rock mechanics. The calculation cycle involves an explicit numerical scheme with a very small time step, as discussed in detail by Cundall and Strack (1979). This method has been applied to processes such as particle mixing in a rotating cylinder (Wightman et al., 1998), horizontal and vertical screw conveyors (Shimizu and Cundall, 2001), filling and discharge of a plane rectangular silo (Masson and Martinez, 2000), deformation of particulate materials under bulk compressive loading (Raji and Favier, 2004a, 2004b), and simulation of soybean bulk properties (Boac et al., 2010).

DEM modeling treats the particle interactions as a dynamic process and assumes that an equilibrium state develops whenever the internal forces in the system balance (Theuerkauf et al., 2007). Contact forces and displacement of a stressed particle assembly are found by tracking the motion of individual particles. Particle motion results from disturbances that propagate through the assembly. The mechanical behavior of the system is described by the motion of each particle and the force and moment acting at each contact. Newton's second law of motion gives the relationship between the particle motion and the forces acting on each particle. Translational and rotational motions of particle are discussed in detail by Remy et al. (2009).

Particles interact only at contact points, with their motion independent of other particles. Forces on particles at contact points include the contact force and the viscous contact damping force (Zhou et al., 2001). These forces have normal and tangential components. The soft-sphere approach commonly used in DEM models allows particles to overlap, giving realistic deformation at contact areas. Overlaps of particles representing local deformation at contacts are small in comparison to the particle size.

The force-displacement law required at the contact point is often represented by Hertz-Mindlin contact model (Mindlin, 1949; Mindlin and Deresiewicz, 1953; Tsuji et al., 1992; Di Renzo and Di Maio, 2004, 2005). This nonlinear model features both the accuracy and simplicity derived from combining Hertz's theory in the normal direction and the Mindlin model in the tangential direction (Tsuji et al., 1992; Remy et al., 2009). Detailed discussion about the forces acting on the particles at contact point can be obtained in Tsuji et al. (1992), Di Renzo and Di Maio (2004), Li et al. (2005), Remy et al. (2009), and DEM Solutions (2010).

For dynamic processes, important factors to consider are the propagation of elastic waves across the particles, the time for load transfer from one particle to adjacent contacting particles, and the need not to transmit energy across a system that is faster than nature ( $\mathrm{Li}$ et al., 2005). In the non-linear contact model (e.g., Hertzian), the critical time step cannot be calculated beforehand, unlike with the linear contact model in which the critical time step is related to the ratio of contact stiffness to particle density. Miller and Pursey (1955) showed that Rayleigh waves or surface waves account for $67 \%$ of the radiated energy, whereas dilational or pressure waves and distortional or shear waves, respectively, are $7 \%$ and $26 \%$ of the radiated energy. All of the energy is assumed to be transferred by the Rayleigh waves since the difference between the speeds of the Rayleigh wave and the distortional wave is small and the energy transferred by the dilational wave is negligible (Li et al., 2005). The average time of arrival of the Rayleigh wave at any contact is the same irrespective of the location of the contact point. The Rayleigh time step, therefore, is the idealized DEM time step and is calculated based on the average particle size (Li et al., 2005; DEM Solutions, 2010). It is a theoretical maximum time step for a DEM simulation of a quasi-static particulate collection in which the coordination number (total number of contacts per particle) for each particle remains above 1 . The detailed equations are given by Li et al. (2005) and DEM Solutions (2010).

In practice, some fraction of the maximum value of the idealized Rayleigh time step is used. For high coordination numbers (4 and above), a typical time step of $20 \%$ of the Rayleigh time step has been shown to be appropriate. However, for lower coordination numbers, $40 \%$ is more suitable (DEM Solutions, 2010). 
Table 1. Initial quality and characteristics of soybeans before transfers. ${ }^{\text {[a] }}$

\begin{tabular}{|c|c|c|c|c|c|c|c|c|c|}
\hline Soybeans & Grade & Impurity $_{(\%)}^{[\mathrm{b}]}$ & $\begin{array}{c}\text { Damaged } \\
\text { Kernels } \\
(\%)\end{array}$ & $\begin{array}{c}\text { Foreign } \\
\text { Material } \\
(\%)\end{array}$ & $\begin{array}{c}\text { Splits } \\
(\%)\end{array}$ & $\begin{array}{c}\text { Mass of } \\
1000 \text { Kernels } \\
(\mathrm{g})\end{array}$ & $\begin{array}{c}\text { Test } \\
\text { Weight } \\
\left(\mathrm{kg} \mathrm{m}^{-3}\right)\end{array}$ & $\begin{array}{r}\text { Moisture } \\
\text { Content } \\
\text { (\% w.b.) }\end{array}$ & $\begin{array}{l}\text { Particle } \\
\text { Density } \\
\left(\mathrm{g} \mathrm{cm}^{-3}\right)\end{array}$ \\
\hline Red & U.S. No. 1 & 0 & $\begin{array}{l}0.337 \mathrm{a} \\
(0.131)\end{array}$ & $\begin{array}{l}0.030 \mathrm{a} \\
(0.013)\end{array}$ & $\begin{array}{l}1.114 \mathrm{a} \\
(0.167)\end{array}$ & $\begin{array}{c}138.90 \mathrm{a} \\
(4.46)\end{array}$ & $\begin{array}{c}700.72 \mathrm{a} \\
(3.21)\end{array}$ & $\begin{array}{l}9.75 \mathrm{a} \\
(0.23)\end{array}$ & $\begin{array}{c}1.24 \mathrm{a} \\
(0.003)\end{array}$ \\
\hline Clear & U.S. No. 1 & 0 & $\begin{array}{l}1.207 \mathrm{~b} \\
(0.486)\end{array}$ & $\begin{array}{l}0.013 \mathrm{~b} \\
(0.008)\end{array}$ & $\begin{array}{l}0.329 \mathrm{~b} \\
(0.103)\end{array}$ & $\begin{array}{c}159.73 \mathrm{~b} \\
(5.15)\end{array}$ & $\begin{array}{c}728.75 \mathrm{~b} \\
(1.48)\end{array}$ & $\begin{array}{c}10.09 \mathrm{~b} \\
(0.34)\end{array}$ & $\begin{array}{c}1.25 \mathrm{~b} \\
(0.004)\end{array}$ \\
\hline
\end{tabular}

[a] Means within a column followed by the same letter are not significantly different at the 5\% level of significance in Bonferroni multiple comparison test (values in parentheses are standard deviations from five experiments).

[b] Impurity $=$ red soybeans in clear, or clear soybeans in red.

\section{Pilot-Scale Boot Experiment}

Validation tests were performed by handling soybeans in a pilot-scale B3 bucket elevator leg (Universal Industries, Inc., Cedar Falls, Iowa). The boot is the enclosed base of the elevator leg casing, where static grain, called residual grain, accumulates after material loading.

\section{Grain Materials}

Two types of soybeans were used for the grain commingling tests in the B3 leg. Test material 1 was red-dyed soybeans with clear hilum from a 2008 crop of variety KS4702. Five bags of these red-dyed soybeans were obtained from the Kansas State University (KSU) Agronomy Farm on January 30, 2009. The bags had a mean mass of $25.7 \mathrm{~kg}$. Test material 2 was clear or uncolored soybeans with brown and black hilum from a 2008 crop. The clear soybeans were purchased from a local elevator on December 4, 2008, and were cleaned through a fanning mill at the KSU Agronomy Farm on December 5, 2008. After cleaning, the clear soybeans were then transferred in five grain tote bags with a mean mass of $563.9 \mathrm{~kg}$ (standard deviation, $\mathrm{SD}=84.07 \mathrm{~kg}$ ) for each bag.

Representative samples from both test materials were collected using a grain probe (USDA, 1995) and were graded (USDA, 2004). Initial moisture content, test weight, foreign material, splits, damaged kernels, 1000-kernel mass, particle density, and impurity (based on the amount of soybeans of different color mixed in the whole lot) were measured. The initial quality and characteristics of red and clear soybeans are shown in table 1 .

\section{TEST FACILITY}

Five tests were performed in the pilot-scale B3 leg at the USDA-ARS Center for Grain and Animal Health Research (CGAHR) in Manhattan, Kansas. The B3 leg is a backfeeding bucket elevator with one hopper and a discharge spout at the end of the elevator head (fig. 1). The metal covers on the right-hand side (RHS) and boot openings were replaced with plexiglass to allow observation of the behavior of the grain inside the boot. The B3 leg has a handling capacity of $6 \mathrm{t} \mathrm{h}^{-1}$ at $75 \%$ bucket filling (manufacturer's data). The B3 leg was operated at a mean soybean mass flow rate of $3.41 \mathrm{t} \mathrm{h}^{-1}$ (range $=3.20$ to $3.65 \mathrm{t} \mathrm{h}^{-1}$ ), which is $41.2 \%$ of the leg's full-cup capacity and corresponds to the same percentage of capacity for the full-scale CGAHR research elevator at an average grain mass flow rate of $47 \mathrm{t} \mathrm{h}^{-1}$ (Ingles et al., 2003).

\section{Test Procedure}

Figure 2 shows a schematic diagram of the grain flow during each grain transfer. The grain transfers simulated the receiving operation of two consecutive grain types without additional (separate) cleaning of equipment between operations. Two types of soybeans of different color and hilum were used to easily identify grain commingling between grain loads.

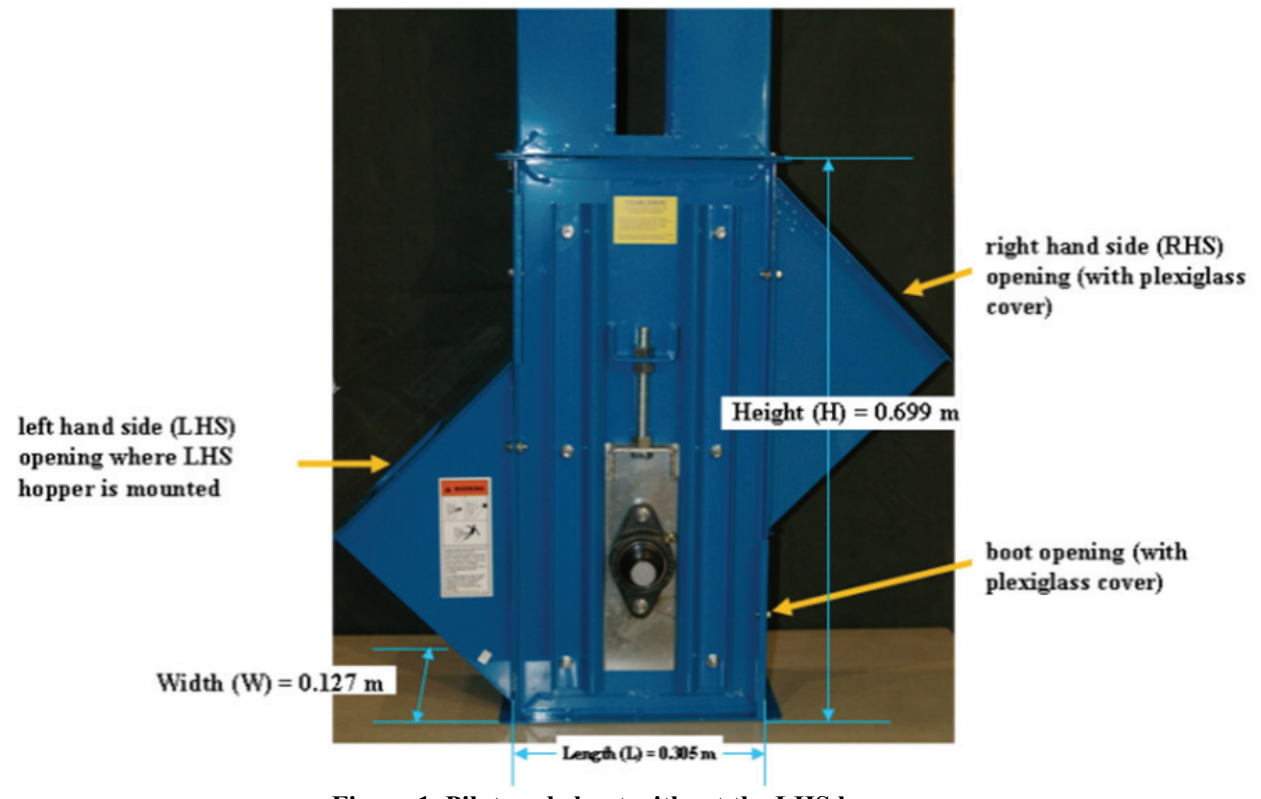

Figure 1. Pilot-scale boot without the LHS hopper. 


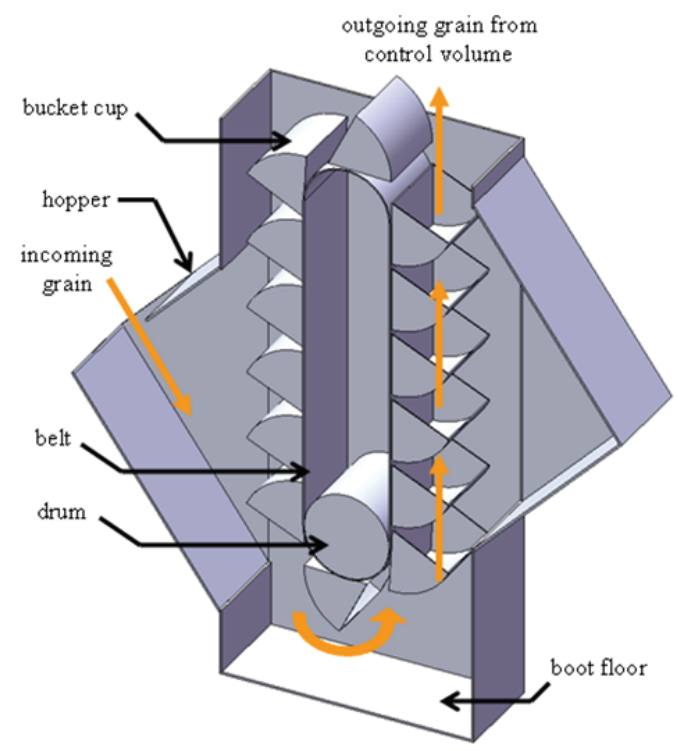

Figure 2. Schematic of grain flow (represented by arrows) in a $B 3$ boot without the LHS hopper.

Prior to each test, the B3 leg was allowed to self-clean by letting the leg run empty for $10 \mathrm{~min}$. Compressed air was used through the RHS opening of the leg (fig. 1) to clean the bucket cups while it was running. Grain residuals and impurities were vacuumed from the boot and other parts of the B3 leg. Before each transfer operation, the ambient and grain temperatures and ambient relative humidity were measured using a mercury thermometer and a psychrometer (model 3312-40, Cole-Parmer Instrument Co., Vernon Hills, Ill.), respectively. The stop of the hopper's slide gate was checked and tightened for proper position, giving the specific opening (width $=32.54 \mathrm{~mm}$ ) for the flow rate of the test. The slide gate width was $127 \mathrm{~mm}$ when fully open.

\section{First Grain Transfer: Red Soybeans}

For each test, red soybeans were transferred through the B3 leg initially to preload the leg and establish red soybeans as the residual grain in the boot. The red soybeans were poured into the hopper. One bag of red soybeans was used per test. A $125 \mathrm{~L}$ plastic container was positioned at the end of the spout to catch the red soybeans discharged from the head of the B3 leg. The B3 leg was switched on, and the slide gate was opened to run the red soybeans. After the transfer of red soybeans, the B3 leg was allowed to continuously run for $5 \mathrm{~min}$ for self-cleaning prior to turning it off. This allowed the red soybeans to stabilize as the residual grain at the boot, and there were no more red soybeans bouncing around inside the leg.

After the red soybean handling, the residual grain heights were measured in the left-hand side (LHS) (i.e., from the top of the LHS opening to the grain) and in the RHS (i.e., from the boot floor to the height of the grain) of the B3 leg. The mean residual grain heights of red soybeans in the LHS and RHS from five tests were 123.2 (SD = $2.78) \mathrm{mm}$ and $95.66(\mathrm{SD}=0.91) \mathrm{mm}$, respectively.

The end of the spout connected to the head was transferred from the plastic container to a Gamet diverter-type (DT) sampler (Seedburo Equipment Co., Chicago, Ill.) to collect grain samples from the next soybean flow. The Gamet DT sampler was placed on top of a plastic hopper $(1.07 \times 1.37 \times 1.59 \mathrm{~m})$ that collected the remainder of the flow.

To accurately record the timing of each sampling, splitcore AC current sensors (model CTV-A, 0 to $20 \mathrm{amp}$, Onset $\mathrm{HOBO}$, Bourne, Mass.) plugged directly into a fourchannel external input data logger (model HOBO H8) was attached to the control panel of the Gamet DT sampler. The clock on a laptop computer (Vaio PCG-Z505R, Sony Electronics, Inc., New York, N.Y.) was synchronized with the HOBO time.

\section{Second Grain Transfer: Clear Soybeans}

Clear soybeans were transferred through the B3 leg after the red soybean transfer was completed. The clear soybean lot was weighed in a tote bag on a digital platform scale (IQ Plus 310A, Rice Lake Weighing System, Inc., Rice Lake, Wisc.). After weighing, the tote bag was placed directly over the hopper of the B3 leg. The protective guard of the tote bag was positioned and opened to initiate filling of the hopper. The tube at the bottom of the tote bag was adjusted to prevent overflow. The height of the tote bag was adjusted to maintain a consistent flow of clear soybeans.

The slide gate of the hopper was opened at the same width for each transfer. The control panel of the Gamet DT sampler was turned on immediately after opening the slide gate. The stopwatch was started when the clear soybeans entered the boot. The real time for this start, as displayed by the laptop clock (in seconds), was recorded. The rotational speed (rpm) of the boot pulley shaft was measured with a digital tachometer (model 1726, Ametek, Largo, Fla.).

\section{GRAIN SAMPLING, SORTING, AND ANALYSIS}

Grain samples were diverted from the flow by the Gamet DT sampler every $15 \mathrm{~s}$ for the first 2 min (mean sample size, $\bar{n}=8, \mathrm{SD}=1$ ), every $30 \mathrm{~s}$ for the next $3 \mathrm{~min}$ $(\bar{n}=6, \mathrm{SD}=1)$, and every $60 \mathrm{~s}$ for the rest of the handling time $(\bar{n}=4, \mathrm{SD}=1)$. The mean sample size was dependent on the total mass of clear soybeans in each of the five grain tote bags. The transfer was completed when the last normal bucket cup scooping was seen through the plexiglass cover. The real time for this complete transfer was recorded as displayed by the laptop clock. The total handling time was also recorded.

After the test, the B3 leg was allowed to self-clean for 5 $\min$. The residual grain heights were measured in the LHS and RHS. The mean residual grain heights of clear soybeans in the LHS and RHS from five tests were 127.0 (SD $=0) \mathrm{mm}$ and $96.09(\mathrm{SD}=1.38) \mathrm{mm}$, respectively. The mean residual grain that was vacuumed from the boot and weighed from the five tests was $2.48(\mathrm{SD}=0.02) \mathrm{kg}$.

Five replicated tests simulated a receiving operation of two consecutive grain types (red and clear soybeans) with only self-cleaning between operations. The grain samples collected by the Gamet DT sampler were weighed. The red soybeans were manually sorted from the clear soybeans. Dividing the sample mass from the experiments by the computed soybean mass in a single bucket cup indicated that each sample represented three bucket cups. 
The average commingling per given load mass $\left(C_{a}, \%\right)$ was computed by:

$$
C_{a}=\frac{\sum_{i=1}^{n}\left(\dot{m}_{s_{i}} \times t_{i} \times\left(\frac{m_{r_{i}}}{m_{r_{i}}+m_{c_{i}}}\right)\right)}{\sum_{i=1}^{n}\left(\dot{m}_{s_{i}} \times t_{i}\right)} \times 100
$$

where $\dot{m}_{S_{i}}$ is the mass flow rate of soybeans $\left(\mathrm{kg} \mathrm{s}^{-1}\right), t_{i}$ is the sampling time interval (s), $m_{r_{i}}$ is the mass of red soybeans $(\mathrm{kg}), m_{c_{i}}$ is the mass of clear soybeans $(\mathrm{kg})$, and $n$ is the number of samples. The mass of grain in a bucket cup $\left(\mathrm{g} \mathrm{cup}^{-1}\right)$ was computed based on the mean mass flow rate of soybeans $\left(\mathrm{g} \mathrm{s}^{-1}\right)$ and the measured bucket cup rate $\left(\operatorname{cup~s}^{-1}\right)$.

\section{Particle Model}

The particle model developed by Boac et al. (2010) for soybeans was implemented in this study. The model was a single-sphere particle model with the following properties: particle coefficient of restitution of 0.6 , particle static friction of 0.45 for soybean-soybean contact $(0.30$ for soybeansteel interaction), particle rolling friction of 0.05 , normal particle size distribution with standard deviation factor of 0.4 , and particle shear modulus of $1.04 \mathrm{MPa}$. Table 2 lists the physical properties of the soybeans and surfaces used in the simulation.

\section{Simulation of Grain Commingling 3-D MODELING OF GRAIN COMMINGLING}

A 3-D model based on the pilot-scale bucket elevator leg geometry (model B3, Universal Industries, Inc., Cedar Falls, Iowa) in the experiments was used to determine grain commingling (fig. 1). Geometries of the pilot-scale bucket elevator boot were drawn in a computer-aided design (CAD) software package (DS SolidWorks Corp., Concord, Mass.) and imported to establish model geometries in the DEM software (fig. 3). The material for the bucket cups

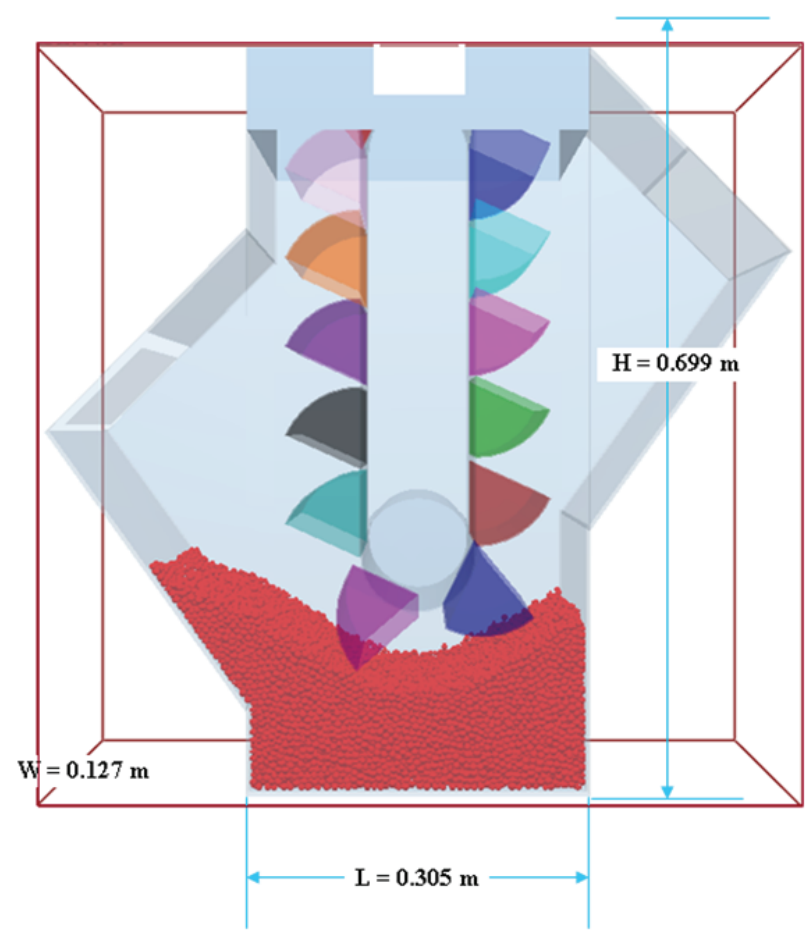

Figure 3. Initial 3-D test model of pilot-scale boot with red soybeans.

and enclosure of the leg was specified as steel, and the belt was rubber (table 2). The input parameters for a singlesphere particle model for the soybean kernel (Boac et al., 2010) are listed in table 2. Simulations were performed at $20 \%$ Rayleigh time steps (table 2). The DEM modeling software used was EDEM 2.3 (DEM Solutions, Hanover, N.H.). The force-displacement law at contact points for all simulations was represented by a Hertz-Mindlin no-slip contact model (DEM Solutions, 2010).

Simulation of an initial 3-D test model was performed first to establish basic model characteristics. In this initial simulation, red soybean particles were handled first in the boot geometries of the 3-D test model (fig. 3). The elevator leg was allowed to run until the residual grain stabilized. After handling red soybeans, the mass of residual grain was determined by extracting the particle mass remaining in the

Table 2. Input parameters for DEM modeling.

\begin{tabular}{|c|c|c|c|c|c|}
\hline Variable & Symbol & Red Soybean & Clear Soybean & Steel & Rubber \\
\hline Particle coefficient of restitution & $e$ & $0.60^{[\mathrm{a}]}$ & $0.60^{[a]}$ & $0.60^{[\mathrm{a}]}$ & $0.60^{[\mathrm{a}]}$ \\
\hline Particle coefficient of static friction (soybean on) & $\mu_{s}$ & $0.45^{[\mathrm{a}]}$ & $0.45^{[\mathrm{a}]}$ & $0.30^{[\mathrm{a}]}$ & $0.50^{[\mathrm{a}]}$ \\
\hline Particle coefficient of rolling friction & $\mu_{r}$ & $0.05^{[\mathrm{a}]}$ & $0.05^{[\mathrm{a}]}$ & $0.05^{[\mathrm{a}]}$ & $0.05^{[\mathrm{a}]}$ \\
\hline Particle size distribution & PSD & Normal $^{[\mathrm{a}]}$ & Normal $^{[\mathrm{a}]}$ & - & - \\
\hline Mean factor & MF & $1.0^{[\mathrm{a}]}$ & $1.0^{[\mathrm{a}]}$ & - & - \\
\hline Standard deviation factor & SDF & $0.4^{[\mathrm{a}]}$ & $0.4^{[\mathrm{a}]}$ & - & - \\
\hline Particle shear modulus $(\mathrm{Pa})$ & $G$ & $1.04 \mathrm{E}+06^{[\mathrm{a}]}$ & $1.04 \mathrm{E}+06^{[\mathrm{a}]}$ & $7.00 \mathrm{E}+10^{[\mathrm{b}, \mathrm{c}, \mathrm{e}]}$ & $1.00 \mathrm{E}+06^{[\mathrm{b}, \mathrm{d}]}$ \\
\hline Particle Poisson's ratio & $v$ & $0.25^{[\mathrm{a}]}$ & $0.25^{[\mathrm{a}]}$ & $0.30^{[\mathrm{b}, \mathrm{c}, \mathrm{e}]}$ & $0.45^{[\mathrm{b}, \mathrm{d}}$ \\
\hline Particle Young's modulus $(\mathrm{Pa})$ & E & $2.60 \mathrm{E}+06^{[\mathrm{a}]}$ & $2.60 \mathrm{E}+06^{[\mathrm{a}]}$ & $1.82 \mathrm{E}+11^{[\mathrm{b}, \mathrm{c}, \mathrm{e}]}$ & $2.90 \mathrm{E}+06^{[\mathrm{b}, \mathrm{d}]}$ \\
\hline Particle density $\left(\mathrm{kg} \mathrm{m}^{-3}\right)$ & $\rho$ & $1243^{[\mathrm{f}]}$ & $1247^{[\mathrm{f}]}$ & $7800^{[\mathrm{b}, \mathrm{c}, \mathrm{e}]}$ & $9100^{[\mathrm{b}, \mathrm{d}]}$ \\
\hline Particle mass $(\mathrm{g})$ & $m$ & $0.1597^{[\mathrm{f}]}$ & $0.1389^{[\mathrm{f}]}$ & - & - \\
\hline Particle radius $(\mathrm{mm})$ & $R$ & $3.13^{[\mathrm{g}]}$ & $2.985^{[\mathrm{g}]}$ & - & - \\
\hline Particle generation rate (particles s ${ }^{-1}$ ) & - & 5,931 & 6,819 & - & - \\
\hline Calculated Rayleigh time step (s) & - & $3.71 \mathrm{E}-04$ & $3.54 \mathrm{E}-04$ & - & - \\
\hline Simulation time step (s) & - & 7.08E-05 & $7.08 \mathrm{E}-05$ & - & - \\
\hline [a] Boac et al. (2009). & \multicolumn{5}{|c|}{ [e] Baumeister et al. (1978). } \\
\hline [b] DEM Solutions (2009). & \multirow{2}{*}{\multicolumn{5}{|c|}{$\begin{array}{l}\text { [f] Measured values. } \\
\text { [g] Calculated values }\end{array}$}} \\
\hline [c] Boresi and Schmidt (2003). & & & alues. & & \\
\hline [d] Ciesielski (1999). & & & & & \\
\hline
\end{tabular}


boot geometry. With red soybean particles as the residual grain in the 3-D leg geometry, clear soybean particles were run next for approximately $5 \mathrm{~min}$ in simulation time. The total particle mass of red and clear soybeans was determined from each bucket cup. The average commingling data were computed based on equation 1 and plotted at time intervals matching the experiments.

In the validation experiment, discussed in the previous sections, the belt of the bucket elevator leg was not rigid and swayed away from the boot pulley, making the gap between the bucket cups and the boot wall smaller. This smaller gap was termed the dynamic gap. In the initial 3-D test model, the belt was rigid, making the gap wider (i.e., static gap = $28.95 \mathrm{~mm}$ ), enabling more soybeans to slip back to the boot bottom without the bucket cup collecting them (fig. 4a).

The static gap in the initial 3-D test model with a rigid belt was reduced to the dynamic gap in the 3-D model, matching the B3 boot. Two dynamic gaps were tested: $14.48 \mathrm{~mm}$, which was inclusive of the measured gap while the bucket cups were moving in the experiment (14.29 to $22.23 \mathrm{~mm}$ ), and $9.525 \mathrm{~mm}$, which was the minimum measured gap observed when the bucket cups were at rest and occurred when the cups swayed closest to the wall. The dynamic gap was measured by inserting a wooden object in the side of the running leg, letting it be hit by the bucket cups, and marking the point where the cups hit.

There are two ways to adjust for the dynamic gap in the CAD drawing of the boot geometry. One method is to move the belt and bucket cups assembly toward the front loading side (i.e., the RHS of the geometry) in the CAD drawing. The other method is to add additional boot material, i.e., a secondary RHS wall placed at a specified distance (or dynamic gap) between the center pulley and the original RHS wall of the boot geometry (fig. 4b). This additional material was incorporated into the CAD drawing of the boot geometry after importing it to EDEM. This latter method was followed because it did not affect the incoming flow of soybeans and it also contributed to accurately matching the residual grain mass in the experiment.

The best dynamic gap for the 3-D model from the preliminary test simulation was $14.48 \mathrm{~mm}$. It was closer to the actual value when the bucket cups were moving, and it gave an average flow rate of clear soybeans and average commingling simulation results that were closer to the actual experimental results than the other tested dynamic gap value. This dynamic gap was implemented in the simulations of the 3-D model matching the B3 boot.

Different dimensions of the gate opening of the LHS hopper $(1 / 4,1 / 3,2 / 5,5 / 12,1 / 2,3 / 4$, and fully open) were also tested. The best gate opening was $2 / 5$ open, (i.e., 50.8 $\mathrm{mm}$ ) because it gave a flow rate matching that of the experiments. Preliminary simulations also investigated different filling times for the LHS hopper to accumulate the proper amount of clear soybeans in the LHS hopper. It was found that $15 \mathrm{~s}$ of filling time for the LHS hopper was appropriate to maintain the flow rate desired for clear soybeans. These details were incorporated into the 3-D model matching the B3 boot.

Simulation of grain commingling in the 3-D model matching the $\mathrm{B} 3$ boot was performed in the same way as in

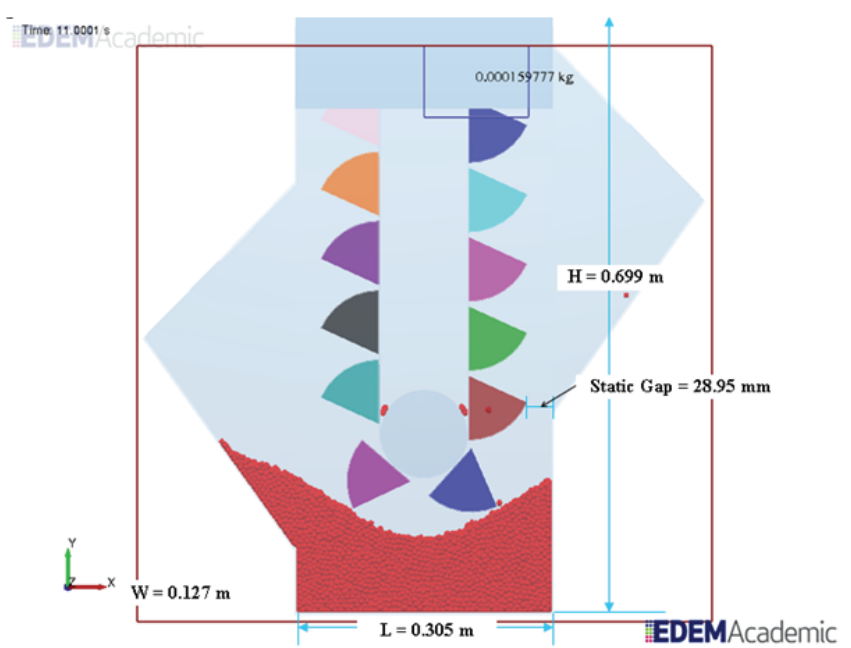

(a)

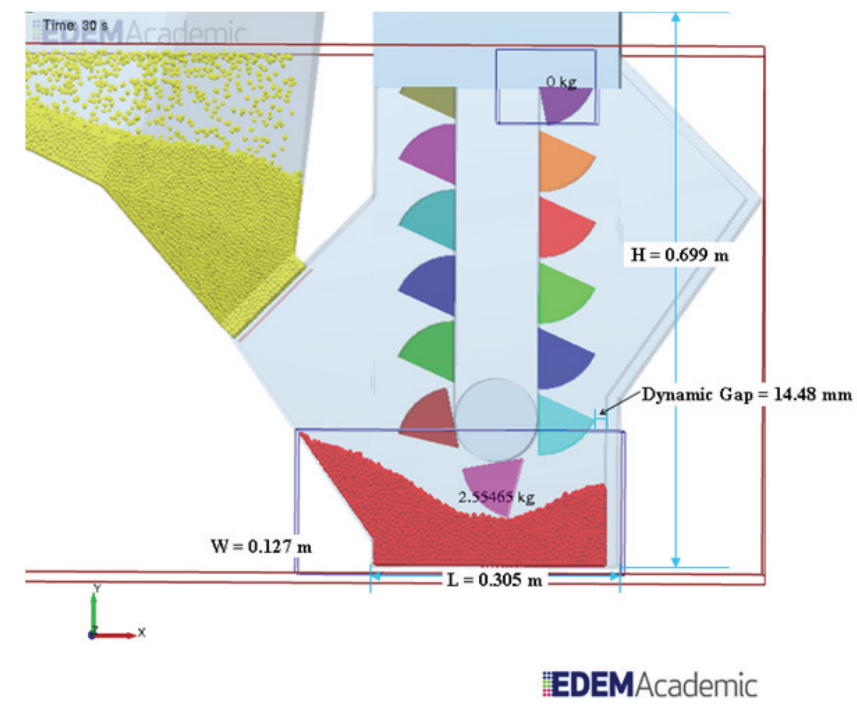

(b)

Figure 4. (a) Initial 3-D test model showing static gap and (b) 3-D model showing dynamic gap.

the initial 3-D test model. Red soybeans were handled first in the boot geometries and allowed to stabilize as a residual grain for $15 \mathrm{~s}$. The mass of the residual grain was then determined by extracting the particle mass remaining in the boot geometry.

The observed sudden surge of particles from the hopper when the slide gate was opened in the experiment was included in the 3-D model of the B3 boot. This surge flow stirs up more particles initially than would be simulated without the surge flow. To implement the sudden particle surge in the B3 boot model, a closed slide gate was modeled. With red soybean particles remaining in the 3-D boot geometry as the residual grain, clear soybeans were generated and allowed to accumulate in the LHS hopper for $15 \mathrm{~s}$ before opening the slide gate (fig. 5a). When the gate was opened, a sudden surge of particles was observed in the simulation (figs. 5b and 5c). After the surge flow, the clear soybean flow was maintained at a constant rate but without the "push" provided by the sudden surge flow (fig. 5d). Clear soybeans were then continuously run in the boot for approximately $8 \mathrm{~min}$ in simulation time. 


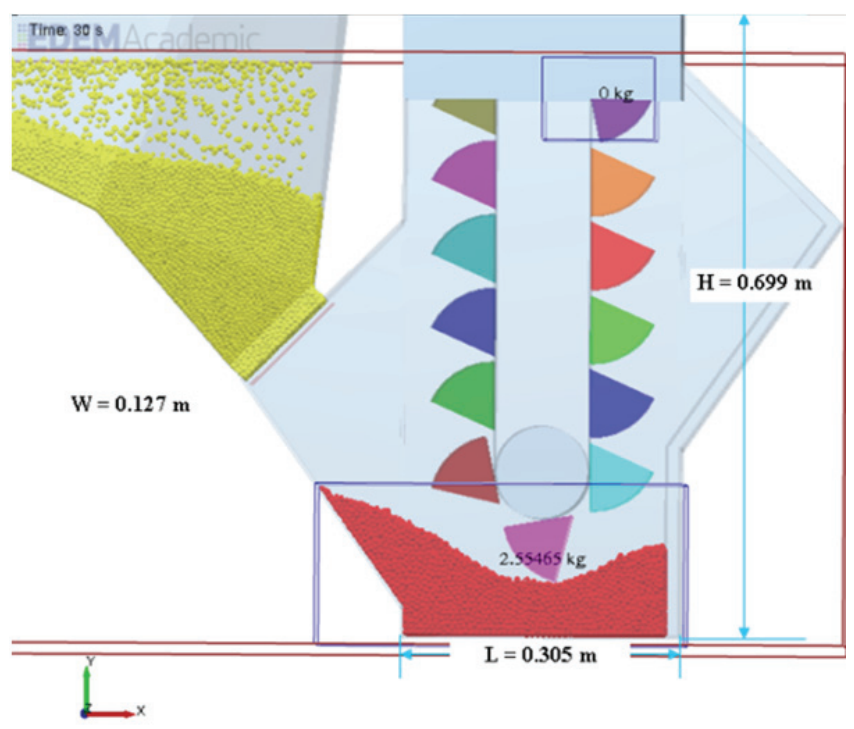

IEDEMAcademic

(a)

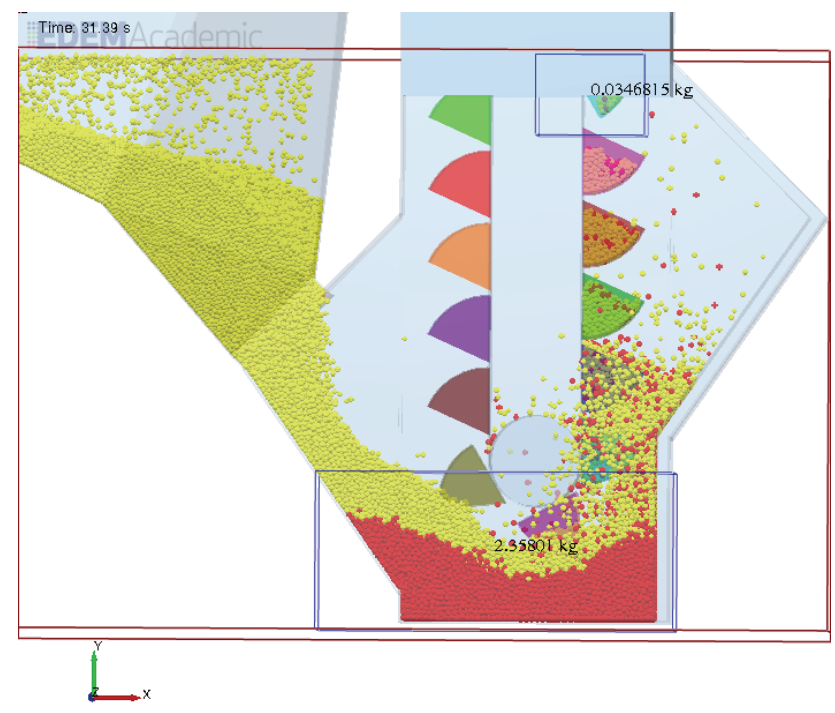

"EDEMAcademic

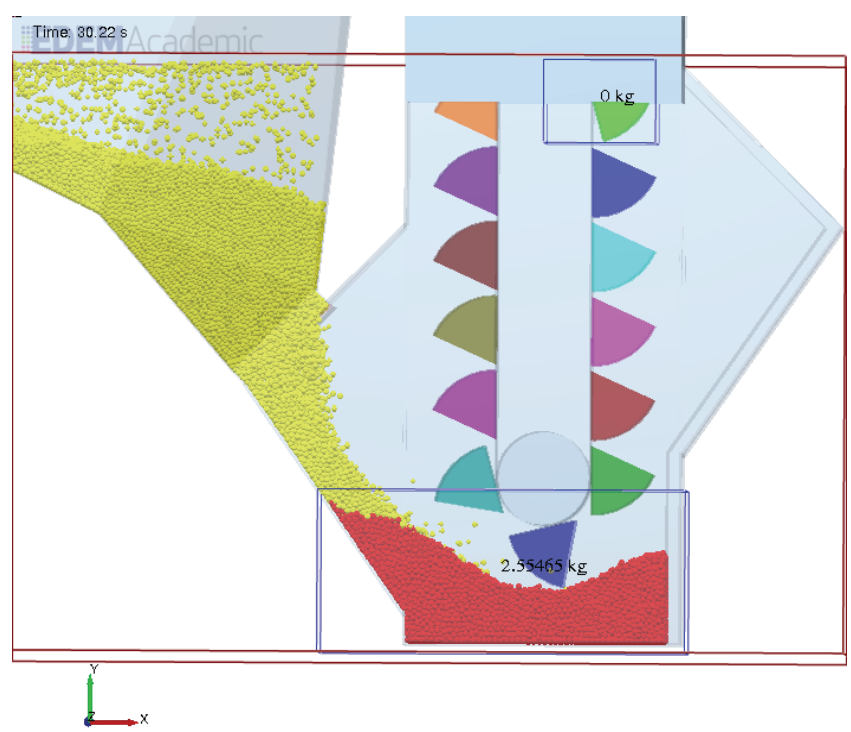

EDEMAcademic

(b)

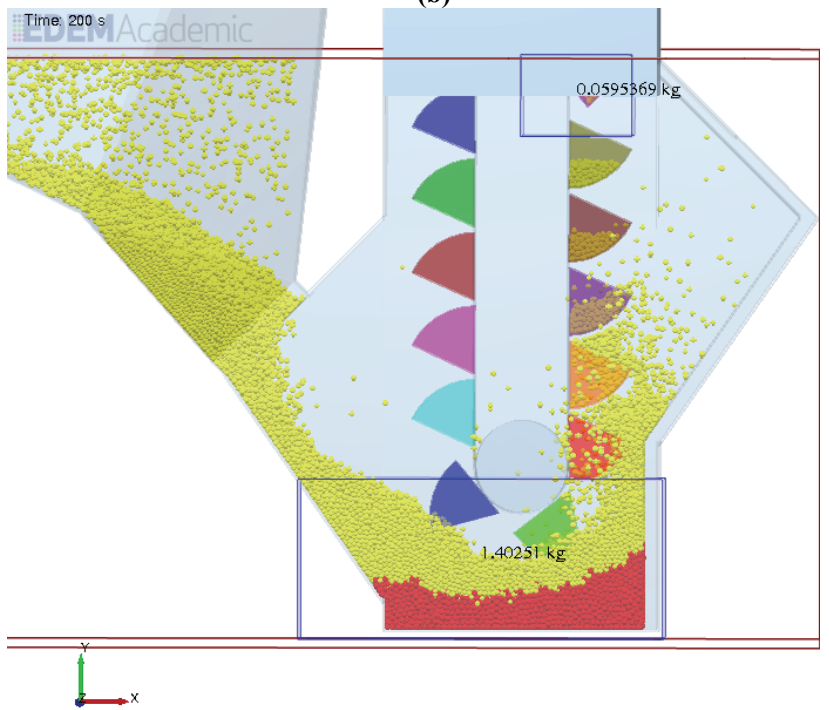

EEDEMAcademic

(d)

Figure 5. 3-D model of $B 3$ boot with particles: (a) accumulating at the gate, (b, c) with surge flow, and (d) long after the surge flow.

The average commingling data were computed based on equation 1 and plotted at time intervals matching the experiments. The trend of average commingling from the 3-D model of the B3 boot was compared with the experimental data.

The start time for sampling was calculated based on the best estimated initial time simulating the experimental validation. The time for the soybeans to be scooped by bucket cups to the time they were collected in the Gamet DT sampler was measured to be $5.0 \mathrm{~s}$. Simulation data times were adjusted accordingly.

The difficulty of matching the initial time in the experiments to that in the simulations was an important issue for the accuracy in time of predicted commingling. The time of initial particle uptake in the experiments was carefully timed with a stopwatch and then carefully matched to the initial uptake of particles in the 3-D simulation.

\section{QUASI-2-D Modeling OF Grain CoMmingling}

To simplify the model and reduce computational time, a quasi-2-D model was investigated for the B3 pilot-scale bucket elevator boot. The same geometries of the B3 boot drawn in the CAD software were imported to establish model geometries in the quasi-2-D simulation.

Quasi-2-D models utilize a 3-D system but with only a fixed width slice of the 3-D geometry, usually equivalent to a given number of particle diameters. A quasi-2-D model is usually preferable to a true 2-D model because, unlike a 2$\mathrm{D}$ model, it can capture the 3-D effects of interacting spheres. Likewise, it is also preferable to a 3-D model because it reduces computational time (Boac et al., 2010).

To generate a quasi-2-D model of the pilot-scale boot, the dimension in the $z$-direction (i.e., width) of the boot was reduced by using periodic boundaries on both the front and back walls. Periodic boundary conditions enable any parti- 
Table 3. Input parameters for the quasi-2-D boot models with reduced control volume.

\begin{tabular}{|c|c|c|c|c|c|c|}
\hline \multirow[b]{2}{*}{ Variable } & \multirow[b]{2}{*}{ Symbol } & \multicolumn{5}{|c|}{ Quasi-2-D Boot Model } \\
\hline & & $4 d$ & $5 d$ & $6 d$ & $7 d$ & $5.6 d$ \\
\hline Particle diameter (mm) & $d$ & 6.26 & 6.26 & 6.26 & 6.26 & 6.26 \\
\hline Width of bucket cup of B3 leg (mm) & $w_{b c}$ & 95.25 & 95.25 & 95.25 & 95.25 & 95.25 \\
\hline Width of quasi-2-D model (mm) & $w_{r C V}$ & 25.04 & 31.30 & 37.56 & 43.82 & 35.06 \\
\hline Reduction factor (dimensionless) & $\zeta_{n}$ & 3.80 & 3.00 & 2.50 & 2.17 & 2.72 \\
\hline Original mass flow rate $\left(\mathrm{kg} \mathrm{s}^{-1}\right)$ & $\dot{m}_{0}$ & 0.95 & 0.95 & 0.95 & 0.95 & 0.95 \\
\hline Mass flow rate for quasi-2-D model $\left(\mathrm{kg} \mathrm{s}^{-1}\right)$ & $\dot{m}_{n}$ & 0.25 & 0.32 & 0.38 & 0.44 & 0.35 \\
\hline $\begin{array}{r}\text { Original particle rate }\left(\text { particles } \mathrm{s}^{-1}\right) \\
\text { Red soybeans } \\
\text { Clear soybeans } \\
\end{array}$ & $\dot{n}_{0}$ & $\begin{array}{l}5,931 \\
6,819 \\
\end{array}$ & $\begin{array}{l}5,931 \\
6,819 \\
\end{array}$ & $\begin{array}{l}5,931 \\
6,819 \\
\end{array}$ & $\begin{array}{l}5,931 \\
6,819 \\
\end{array}$ & $\begin{array}{l}5,931 \\
6,819 \\
\end{array}$ \\
\hline $\begin{array}{l}\text { Particle rate for quasi-2-D model (particles s }{ }^{-1} \text { ) } \\
\text { Red soybeans } \\
\text { Clear soybeans }\end{array}$ & $\dot{n}_{n}$ & $\begin{array}{l}1,561 \\
1,794\end{array}$ & $\begin{array}{l}1,977 \\
2,273\end{array}$ & $\begin{array}{l}2,372 \\
2,728\end{array}$ & $\begin{array}{l}2,733 \\
3,142\end{array}$ & $\begin{array}{l}2,181 \\
2,507\end{array}$ \\
\hline
\end{tabular}

cle leaving the domain in that direction to instantly re-enter on the opposite side (DEM Solutions, 2010), simulating infinite length in that direction, thereby eliminating wall effects and reducing the total number of particles inside the control volume. The elimination of wall effects, such as particle-on-wall friction, could potentially reduce simulation accuracy if those effects are large enough in the true 3D case.

Preliminary tests of five quasi-2-D models were performed to determine the acceptable model for quasi-2-D simulation. The models had widths of from four to seven times the mean particle diameter $(d)$ of red soybeans (i.e., $4 d, 5 d, 5.6 d, 6 d, 7 d)$ (table 3 ). The reduction factor $\left(\zeta_{n}\right)$ for each quasi-2-D model is defined as:

$$
\zeta_{n}=\frac{w_{b c}}{w_{Q 2 D}}
$$

where $w_{b c}$ is the original width of the bucket cup, $w_{Q 2 D}$ is the width of the quasi-2-D model (i.e., $4 d, 5 d, 5.6 d, 6 d$, or $7 d$ ), and $n=4,5,5.6,6$, and 7 .

A single-sphere particle model with the same material and interaction properties for the soybeans used in the 3-D model was employed in the quasi-2-D models (Boac et al., 2010). The total number of particles created was also reduced based on the reduction factor (table 3).

Similar to the 3-D modeling, red soybean particles were also handled first in the quasi-2-D model until the residual grain stabilized after a run time of $15 \mathrm{~s}$ (fig. 6a). The red soybeans were left as residual grain. Clear soybeans were allowed to accumulate in the LHS hopper for $15 \mathrm{~s}$ before opening the gate and allowing them to run for approximately $35 \mathrm{~s}$ (fig. 6b). Average commingling for each quasi-2-D model was computed based on equation 1 . The average commingling results from the five candidate quasi-2-D boot models were compared. The final quasi-2-D model with reduced boot width and stable simulation results was selected after evaluating the stability during the preliminary tests. Instability may occur in quasi-2-D models that are too narrow due to a large particle from one side of the periodic boundary touching another side of the same particle on the other side of the periodic boundary (DEM Solutions, 2010).

Quasi-2-D simulation of the B3 boot was performed the same way as with the 3-D model except with the chosen reduced control volume (i.e., equivalent to a given number of particle diameters). The timing of the start of sampling time, particle surge flow, and effective dynamic gap were included in the chosen quasi-2-D model. The best dynamic gap chosen in the 3-D model of the B3 boot was used initially as the effective gap in the quasi-2-D model. Different effective dynamic gaps and filling times of the LHS hopper were tested for the chosen quasi-2-D model. The trends of commingling data from the chosen quasi-2-D model of the B3 boot were compared with the 3-D model and exper-

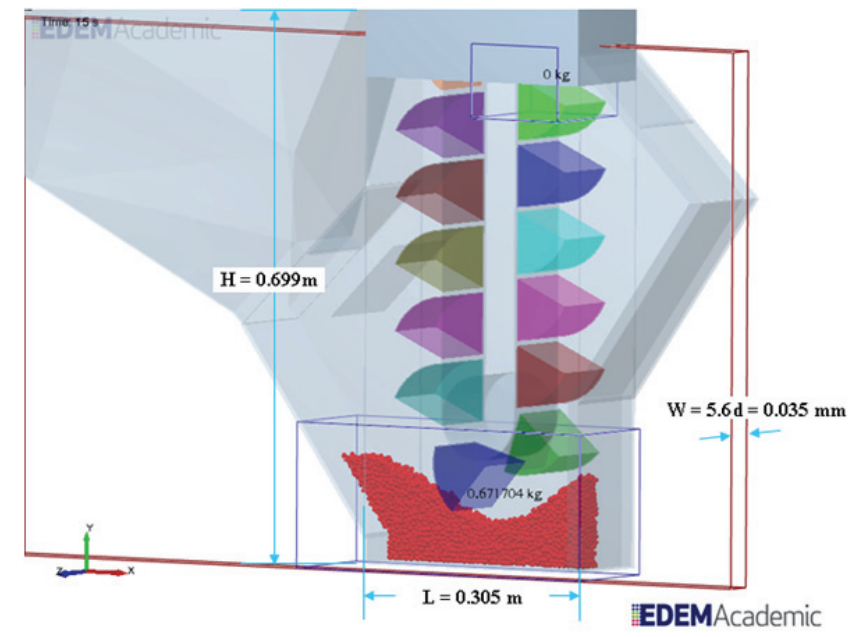

(a)

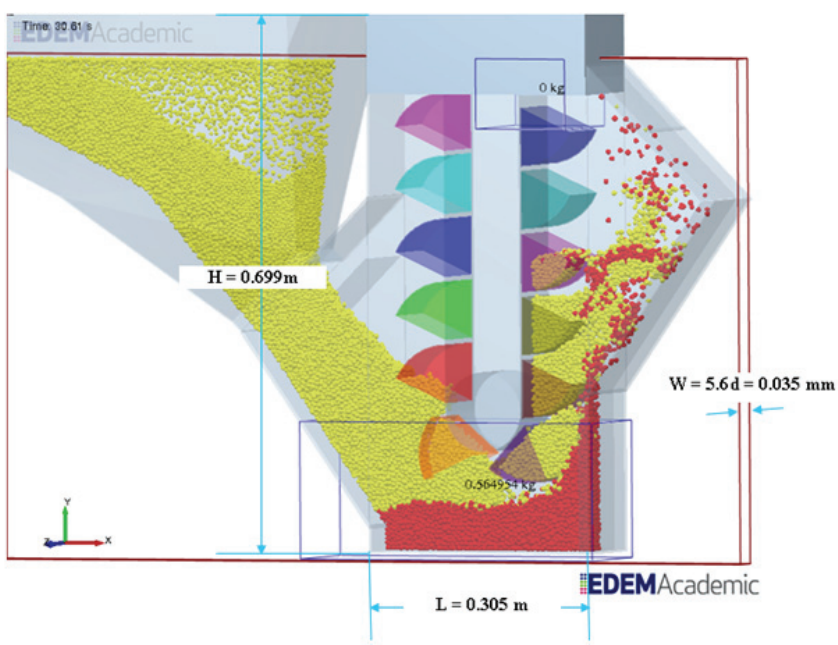

(b)

Figure 6. Quasi-2-D simulation during handling of (a) red and (b) clear soybeans. 


\begin{tabular}{|c|c|c|}
\hline Model & Factors Considered & Remarks \\
\hline \multirow[t]{2}{*}{$\begin{array}{l}\text { Initial 3-D } \\
\text { model }\end{array}$} & Static gap $=28.95 \mathrm{~mm}$ & $\begin{array}{l}\text { Performed to establish basic model characteristics. The belt was rigid, making the gap between the } \\
\text { bucket cups and the RHS boot wall wider, which enabled more soybeans to slip back to the boot } \\
\text { bottom without the bucket cup collecting them. }\end{array}$ \\
\hline & No particle surge & $\begin{array}{l}\text { There was also no particle surge that pushed the red soybeans toward the RHS to mix properly with } \\
\text { the clear soybeans. }\end{array}$ \\
\hline \multirow[t]{4}{*}{ 3-D model } & $\begin{array}{c}\text { Dynamic gap: } \\
14.48 \mathrm{~mm} \text { and } 9.525 \mathrm{~mm}\end{array}$ & $\begin{array}{l}\text { Two dynamic gaps were tested: } 14.48 \mathrm{~mm} \text {, which was inclusive of the measured gap while the } \\
\text { bucket cups were moving in the experiment ( } 14.29 \text { to } 22.23 \mathrm{~mm}) \text {, and } 9.525 \mathrm{~mm} \text {, which was the } \\
\text { minimum measured gap when the bucket cups were at rest and occurred when the cups swayed } \\
\text { close to the wall. The best dynamic gap was } 14.48 \mathrm{~mm} \text {, which was closer to the actual value when } \\
\text { the bucket cups were moving, closely matched the average flow rate of clear soybeans, and gave } \\
\text { average commingling simulation results closer to the actual experimental results. }\end{array}$ \\
\hline & $\begin{array}{l}\text { Slide gate opening: } 1 / 4,1 / 3,2 / 5 \text {, } \\
5 / 12,1 / 2,3 / 4 \text {, or fully open }\end{array}$ & $\begin{array}{l}\text { Different slide gate openings of the LHS hopper were tested. The best gate opening was } 2 / 5 \text { open } \\
\text { (i.e., } 50.8 \mathrm{~mm} \text { ) because it gave a flow rate matching that of the experiments. }\end{array}$ \\
\hline & $\begin{array}{l}\text { LHS hopper filling time: } \\
5 \mathrm{~s}, 10 \mathrm{~s} \text {, or } 15 \mathrm{~s}\end{array}$ & $\begin{array}{l}\text { Different filling times were tested for the LHS hopper to accumulate the proper amount of clear } \\
\text { soybeans. A } 15 \mathrm{~s} \text { filling time was appropriate to maintain the flow rate desired for clear soybeans. }\end{array}$ \\
\hline & With particle surge flow & $\begin{array}{l}\text { The sudden surge of particles from the hopper when the slide gate was opened in the experiment } \\
\text { was implemented in the 3-D model. To implement the surge in the } 3 \text {-D model, the slide gate was } \\
\text { first closed, clear soybeans were allowed to accumulate in the LHS hopper for } 15 \mathrm{~s} \text {, and the slide } \\
\text { gate was then opened. When the gate was opened, a sudden surge of particles was observed in the } \\
\text { simulation. The surge flow stirs up more particles initially than would be simulated without the } \\
\text { surge flow, achieving commingling results that closely matched the experiments in the long run. }\end{array}$ \\
\hline $\begin{array}{l}\text { Quasi 2-D } \\
\text { models }\end{array}$ & $\begin{array}{l}\text { Reduced control volume: } \\
\quad 4 d, 5 d, 5.6 d, 6 d \text {, or } 7 d\end{array}$ & $\begin{array}{l}\text { Performed to determine the acceptable model with reduced control volume. The quasi-2-D model } \\
\text { that had the smallest reduced control volume with stable simulation and safety margin for modeling } \\
(5.6 d) \text { was chosen to model the pilot-scale B3 boot. }\end{array}$ \\
\hline \multirow[t]{2}{*}{$\begin{array}{l}\text { Quasi 2-D } \\
(5.6 d) \\
\text { model }\end{array}$} & $\begin{array}{l}\text { Wider effective gap to account } \\
\text { for edge effects missing in } \\
\text { the quasi-2-D model }\end{array}$ & $\begin{array}{l}\text { Using the effective dynamic gap }(14.48 \mathrm{~mm}) \text { in the quasi-2-D }(5.6 d) \text { model posed a problem that } \\
\text { may be explained by the edge effects that are in the } 3-\mathrm{D} \text { model but not in the quasi-2-D }(5.6 d) \\
\text { model due to the reduced control volume. A wider effective gap was tested to allow more grain to } \\
\text { return to the boot from the missing edge effects in the quasi-2-D model. }\end{array}$ \\
\hline & $\begin{array}{l}\text { LHS hopper filling time: } \\
\qquad 5 \mathrm{~s}, 10 \mathrm{~s} \text {, or } 15 \mathrm{~s}\end{array}$ & $\begin{array}{l}\text { Different filling times of the LHS hopper were used to determine the resulting particle surge that } \\
\text { would match the predicted commingling with that of the experiments. }\end{array}$ \\
\hline
\end{tabular}

mental data. Table 4 summarizes the simulations performed in EDEM using the 3-D and quasi-2-D models.

\section{Data Analysis}

Basic descriptive statistics (i.e., mean and standard deviation) were determined for the parameters evaluated. Experimental data were compared with the 3-D model and quasi-2-D model of the B3 boot at the experimental sampling time intervals. The predicted results were also compared by inspection with the lower and upper limits of the $95 \%$ confidence interval of the experimental data in the plot. The standard error (s.e.) of the model compared with the experiment was computed for each model plot. It was calculated as a point-by-point difference between the model value and the individual experimental value at each experimental sampling time interval using the following equation:

$$
\text { s.e. }=\sqrt{\frac{\sum_{i=1}^{n}\left(Y_{m_{i}}-Y_{e_{i}}\right)^{2}}{n-1}}
$$

where s.e. is standard error, $Y_{m}$ is the model value, $Y_{e}$ is the individual experimental value, and $n$ is the number of samples.

\section{RESULTS AND DISCUSSION EXPERIMENTAL RESULTS}

Average commingling for the five tests started at $4.25 \%$ during the first $5 \mathrm{~s}$, decreased to $2.20 \%$ after $21 \mathrm{~s}$, to $0.42 \%$ after $3.2 \mathrm{~min}$, and eventually reached $0.20 \%$ after $7.7 \mathrm{~min}$. The end result $(0.20 \%)$ for this pilot-scale leg was within the published average cumulative commingling for the combined effect of pit and elevator boot for the full-scale
CGAHR research elevator, which was $0.18 \%$ (Ingles et al., 2003), and for the elevator leg only for a full-scale commercial facility, which was $0.23 \%$ (Ingles et al., 2006). Figure 7 shows $95 \%$ confidence interval (C.I.) limits for the average commingling and was used to compare the predicted results of the simulation models.

From the experiments, the mean mass flow rate for soybeans $\left(\dot{m}_{s}\right)$ was measured as $3.41 \mathrm{t} \mathrm{h}^{-1}\left(0.95 \mathrm{~kg} \mathrm{~s}^{-1}\right)$. The mean boot pulley rotational speed $\left(N_{b}\right)$ and radius of the boot pulley, including belt thickness $\left(r_{b}\right)$, were $203.7 \mathrm{rpm}$ and $0.0535 \mathrm{~m}$, respectively. These values gave a boot belt speed $\left(v_{b}\right)$ of $1.141 \mathrm{~m} \mathrm{~s}^{-1}$. The bucket cup spacing $\left(s_{c}\right)$ and frequency $\left(f_{c}\right)$ were $0.08255 \mathrm{~m} \mathrm{cup}^{-1}$ and 13.82 cups s$^{-1}$, respectively, resulting in mass of grain per bucket cup $\left(m_{b c}\right)$ of $68.54 \mathrm{~g} \mathrm{cup}^{-1}$. These data were incorporated into the simulations using the 3-D model of the B3 pilot-scale boot. The gap between the bucket cups and the right-hand sidewall of the boot was set to $14.48 \mathrm{~mm}$ in the 3-D model (and not in the initial 3-D model), within the range of the measured dynamic gap as discussed above. The initial 3-D model used the static gap $(28.95 \mathrm{~mm})$ since this model was performed first to establish basic model characteristics.

\section{Predicted Grain Commingling WITH THE 3-D BOOT MODEL Initial 3-D Test Model}

The predicted average commingling from the initial 3-D test model followed the trend of, but overpredicted, the experimental data. The overprediction was found to be due to at least two issues: (1) the size of the gap between bucket cups and RHS wall of the boot and (2) the absence of a realistic surge of particles when the slide gate opened to initiate the flow of clear soybeans. The static gap 


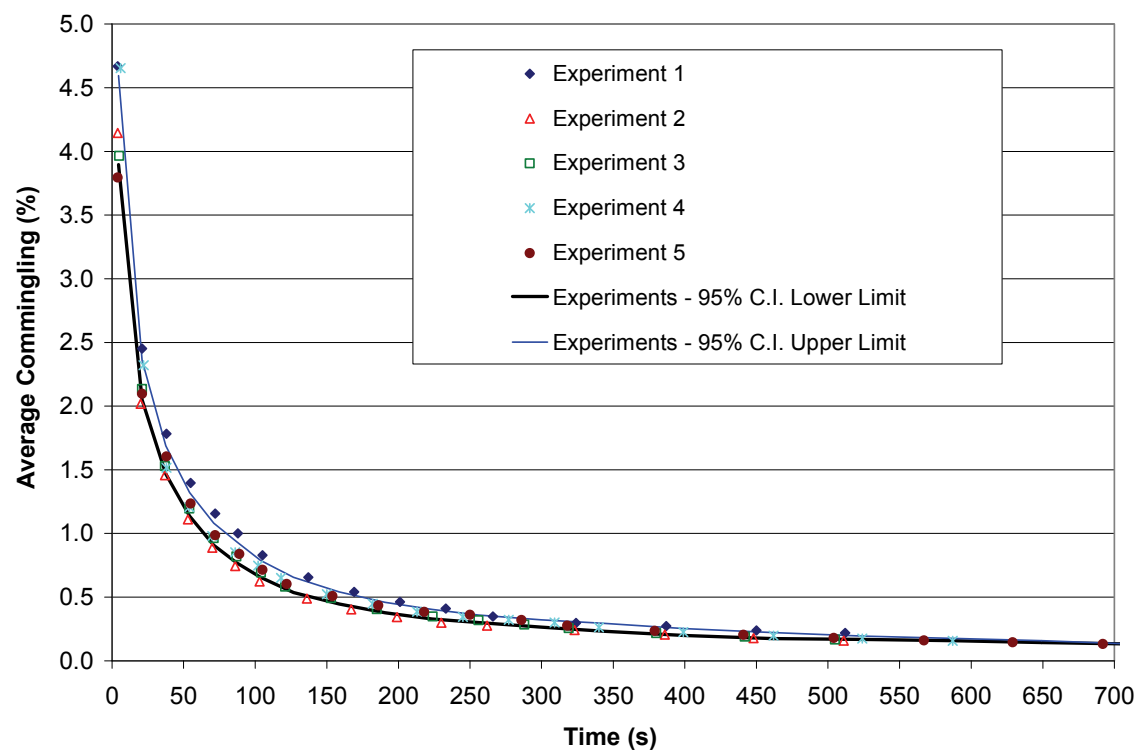

Figure 7. Average commingling from experiments showing $95 \%$ confidence interval (C.I.) limits.

$(28.95 \mathrm{~mm})$ used between the bucket cups and the RHS wall of the boot was larger than the gap found during operation of the leg. The wider static gap allowed more soybeans to slip back to the boot bottom without the bucket cups collecting them early in the experiment. The absence of a surge of clear soybeans after the gate was opened for the second grain also contributed to the overprediction of commingling. The gap between the bucket cups and RHS wall of the boot and the absence of particle surge during the onset of the clear soybean flow were further refined in the succeeding simulations.

\section{Complete 3-D Model for B3 Boot}

Preliminary simulations in the 3-D model were performed to evaluate the most appropriate model details for the B 3 boot. The dynamic gap between the bucket cups and the RHS boot wall was investigated, and a $14.48 \mathrm{~mm}$ gap was chosen because it was closer to the actual value when the bucket cups were moving. Furthermore, it closely matched the average flow rate of clear soybeans and gave average commingling simulation results closer to experimental results. Thus, a dynamic gap of $14.48 \mathrm{~mm}$ was used in the 3-D model.

Figure 8 shows the average commingling results of the best 3-D model (3-D model 1) and the second best 3-D model (3-D model 2), computed at time intervals matching the experiments. The 3 -D model 2 gave a better standard error of the model compared to the experiment (s.e. $=0.82$ ) than 3-D model 1 (s.e. $=1.50)$. Predicted commingling val-

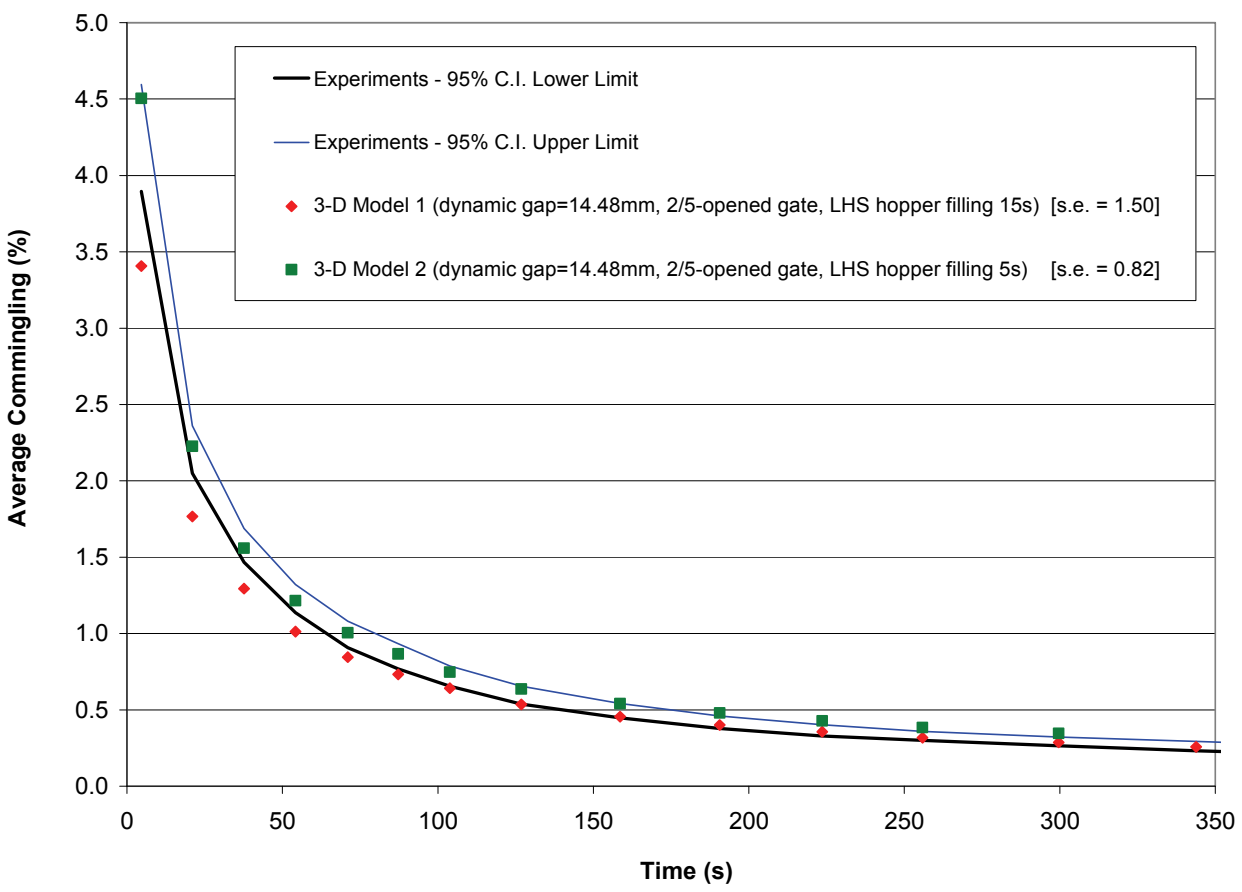

Figure 8. Average commingling from 3-D model 1 and 3-D model 2 compared with 95\% C.I. limits of the experiments, plotted at time intervals matching the experiments. 


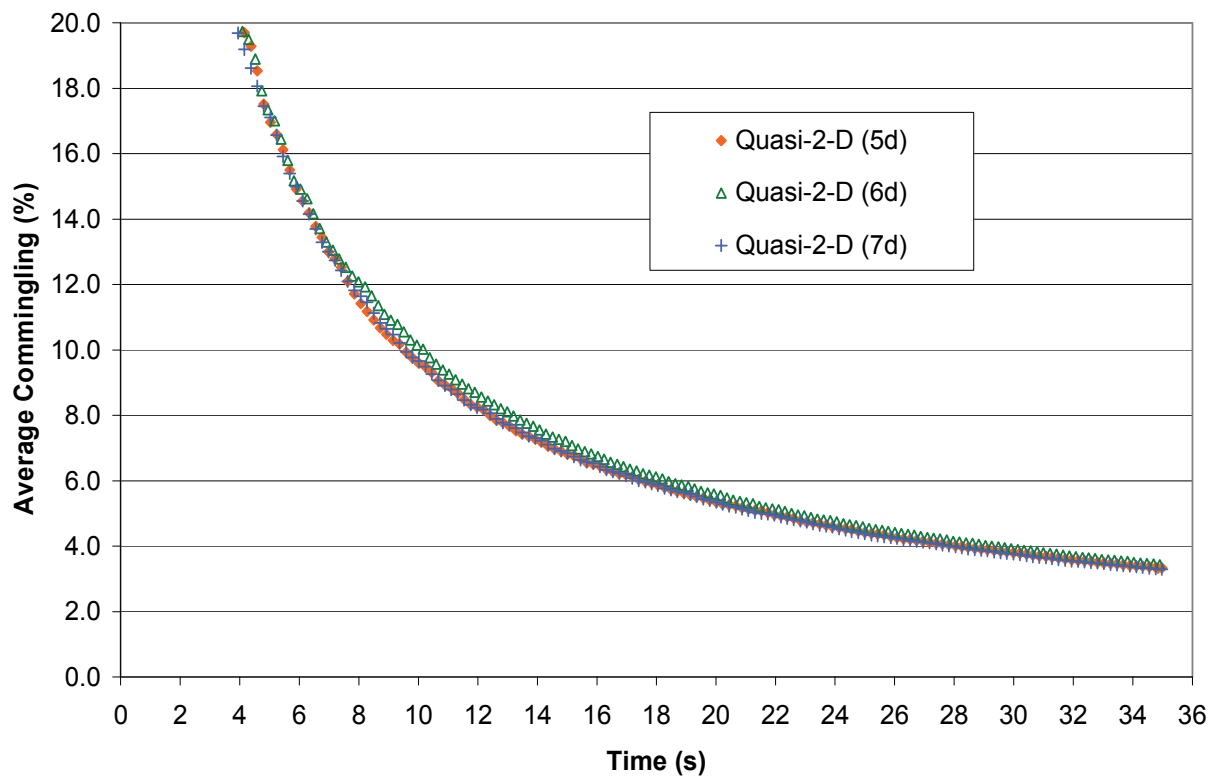

Figure 9. Average commingling from preliminary quasi-2-D models with reduced control volume. (Note: The quasi-2-D (4d) model was unstable.)

ues for 3-D model 2 were within the $95 \%$ confidence limits of the experimental data during the first $100 \mathrm{~s}$; however, they were greater than the experimental values at later times. Thus, 3-D model 1 was chosen as the best 3-D model because, at times longer than $100 \mathrm{~s}$, it closely matched the experimental average commingling. Predictions at longer times were considered more important than during the initial $100 \mathrm{~s}$ because predictions at longer times represent the total commingling for the run, which is of greater interest in field operations than the initial values alone.

\section{Predicted Grain Commingling With THE QUASI-2-D BOOT MODEL}

Predicted commingling results of the quasi-2-D models with different widths or reduced control volumes based on particle diameter $d$ (i.e., $4 d, 5 d, 6 d$, and $7 d$ ) did not vary much (fig. 9), except for the quasi-2-D (4d) model. The quasi-2-D (4d) model did not perform well in the simulation due to instability of the system in the reduced domain. This may have resulted from issues such as the side of a large particle (from one side of the periodic boundary) touching another side of the same particle (on the other side of the periodic boundary), since the periodic boundary conditions enable any particle leaving the domain in that direction to instantly re-enter on the opposite side (DEM Solutions, 2010). Forces from the contact of a particle with itself are expected to be unpredictable, thus making the system unstable. This is also similar to putting a particle into a container of a size smaller than the particle size. The system will be unpredictable, and the particles will be unstable, which was what happened in the quasi-2-D (4d) model.

The quasi-2-D models beginning with $5 d$ up to $7 d$ were stable in the simulations. Their results appear to be invariant with a reduction factor $\zeta_{n}<3.00$, i.e., the quasi-2-D ( $\left.5 d\right)$ model in table 3. Therefore, $\zeta_{n}=2.72$, i.e., the quasi-2-D (5.6d) model, was selected to be slightly conservative because it gave a safety margin for modeling and was the equivalent of the criterion recommended by the software company (Dr. Oleh Baran, formerly with DEM Solutions, Inc., personal communication, 19 Oct. 2009), i.e., four times the maximum particle diameter. Because the $5 d$ model was also stable in these simulations, the greater width of the recommended $5.6 d$ model was considered to provide a safety factor, so the model should remain stable under a wider range of conditions than the narrower $5 d$ model. The invariant results are in agreement with previous studies modeling hopper flow in a solar silo (Joseph et al., 2000) and segregation in hopper flow (Ketterhagen et al., 2008) with periodic boundaries separated by only a smaller value of grain radii.

The quasi-2-D (5.6d) model was also found to be relatively faster than the quasi-2-D $(6 d)$ model. Thus, the quasi-2-D (5.6d) model was implemented for the B3 boot simulations as a faster alternative to the 3-D model.

Including the particle surge and using a dynamic gap of $14.48 \mathrm{~mm}$ in the best 3-D model predicted commingling better than not including these refinements (fig. 8). However, following the dynamic gap of the 3-D model and applying it in the quasi-2-D (5.6d) model underpredicted the commingling (fig. 10). Thus, a wider effective gap was needed for the quasi-2-D model. The first effective gap to be tested was $28.95 \mathrm{~mm}$, which was equivalent to the original static gap. Other effective gaps were not tested since the first one worked well.

The underprediction of the commingling in the quasi-2$\mathrm{D}$ model may be explained by the edge effects that are in the 3-D model but not in the quasi-2-D (5.6d) model due to the reduced control volume. Figure 11 shows the quasi-2-D $(15 d)$ model, where $15 d$ is the full bucket cup width, in which the effective gap was wider than the dynamic gap of the best 3-D model. The wider effective gap allows space for more grain to return to the boot, compensating for the missing edge effects in the quasi-2-D model. The same applies to the quasi-2-D (5.6d) model. 


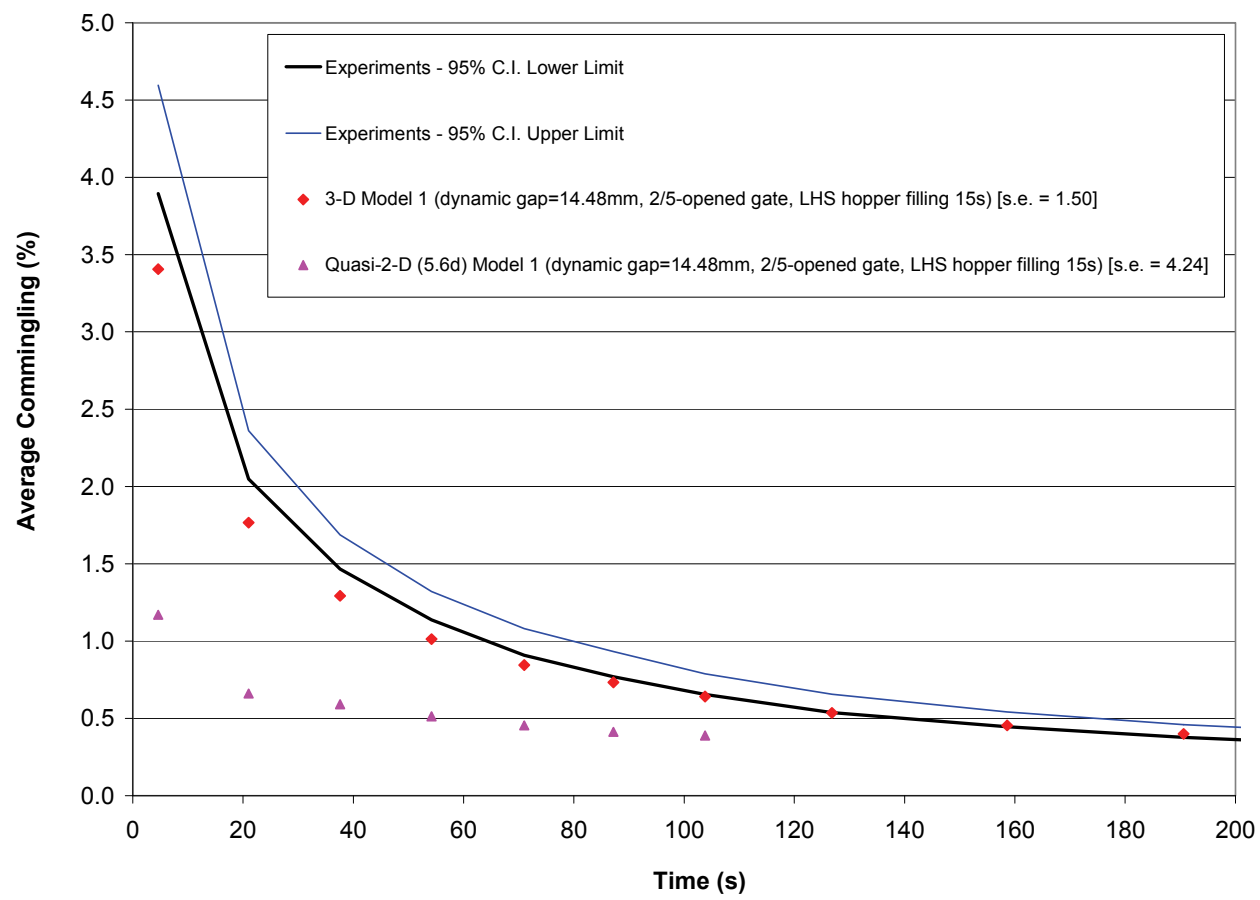

Figure 10. Average commingling from 3-D and quasi-2-D (5.6d) models with the same dynamic gap.

The correct effective gap used for the quasi-2-D (5.6d) model coincidentally equals the original static gap (28.95 $\mathrm{mm})$. The inclusion of the correct effective gap and particle surge flow in the quasi-2-D (5.6d) model predicted the closest value of average commingling to the results of the best 3-D model (fig. 12).

Different filling times of the LHS hopper to vary the particle surge were also tested. Using a $5 \mathrm{~s}$ filling time, quasi-2-D model 1 matched the experimental average commingling for the first $70 \mathrm{~s}$ and then overpredicted the commingling after that time. With a $15 \mathrm{~s}$ filling time, similar to that in 3-D model 1, quasi-2-D model 2 underpredicted the average commingling during the first $100 \mathrm{~s}$, but the results tended to match the experimental average commingling after that time. This may be due to more clear soybeans commingling with the red soybeans in the beginning of the run, thus underpredicting the commingling during the first few seconds. The $10 \mathrm{~s}$ LHS hopper filling time in quasi-2-D model 3 showed results that were between the 5 and $15 \mathrm{~s}$ filling times. Further improvements in the quasi-2-D model might be achieved by testing different LHS hopper
Table 5. Computational time for 3-D and quasi-2-D (5.6d) models. ${ }^{[a]}$

\begin{tabular}{ccc}
\hline & $\begin{array}{c}\text { Computational Time } \\
\text { (actual hours per second } \\
\text { of simulation time) }\end{array}$ & $\begin{array}{c}\text { Percent } \\
\text { Difference } \\
\text { (from 3-D model 1) }\end{array}$ \\
\hline 3-D model 1 & 0.450 & 00.00 \\
Quasi-2-D model 1 & 0.118 & 73.72 \\
Quasi-2-D model 2 & 0.116 & 74.25 \\
Quasi-2-D model 3 & 0.125 & 72.24 \\
\hline
\end{tabular}

[a] Simulations were run on a workstation with two Intel Xeon DP Quad-Core W5580 3.2 GHz processors.

filling times between 5 and $15 \mathrm{~s}$ and running the simulation longer to match the experimental times. Other improvements may be achieved by predicting the effect of vibration on the residual grain mass and height, and investigating different particle properties (i.e., soybean material and interaction properties as well as particle size distribution) in the system.

The quasi-2-D (5.6d) model reduced simulation run time by $72 \%$ to $74 \%$ compared to the $3-\mathrm{D}$ model, with both models being run on the same workstation computer (table 5 ). It is postulated that a greater reduction in time will be achieved in the full-scale boot using a quasi-2-D (5.6d)

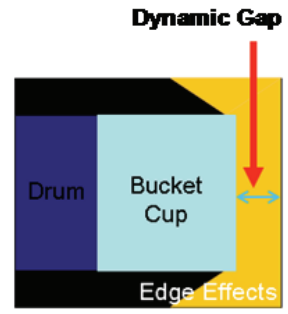

Full Control Volume 3-D Model

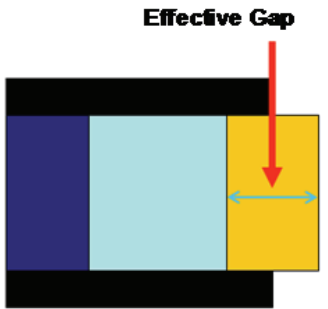

$$
\begin{aligned}
& \text { Reduced Control } \\
& \text { Volume }=15 \mathrm{~d} \\
& \text { Quasi-2-D (15d) } \\
& \text { Model }
\end{aligned}
$$

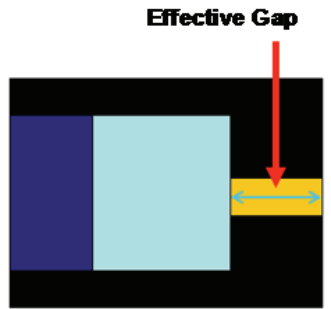

$$
\begin{gathered}
\text { Reduced Control } \\
\text { Volume }=5.6 \mathrm{~d} \\
\text { Quasi-2-D (5.6d) } \\
\text { Model }
\end{gathered}
$$

Figure 11 . Dynamic and effective gaps illustration for full and reduced control volumes. 


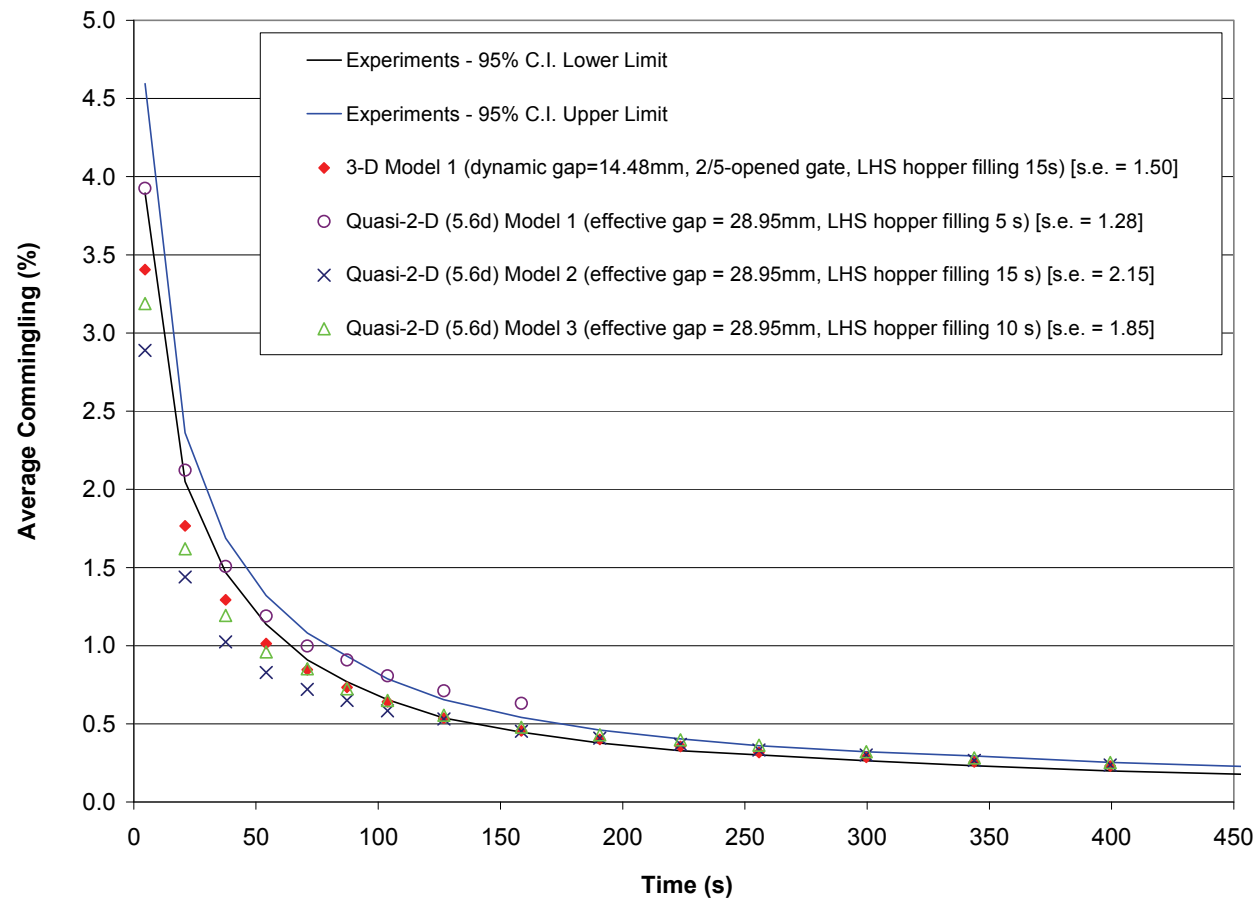

Figure 12. Average commingling from quasi-2-D models using effective gap at different LHS hopper filling times.

model since a full-scale boot will have a boot width much greater than the $15 d$ of the B3 leg boot.

\section{Conclusions}

Grain commingling in a pilot-scale bucket elevator boot was modeled in three-dimensional (3-D) and quasi-twodimensional (quasi-2-D) discrete element method (DEM) simulations. Experiments with grain commingling were performed to validate the DEM models with a pilot-scale boot using soybeans as the test material. The following conclusions were drawn from this research:

- Experimental data showed that mean average commingling started at $4.25 \%$ during the first $5 \mathrm{~s}$, decreased to $2.20 \%$ after $21 \mathrm{~s}$, decreased to $0.42 \%$ after $3.2 \mathrm{~min}$, and eventually decreased to $0.20 \%$ after 7.7 min. The end result was within the published range of average cumulative commingling values for full-size bucket elevator legs.

- Predicted commingling from the initial 3-D pilotscale boot model generally followed the trend of the experimental data but overpredicted the commingling. Refinements of the 3-D model showed that the best 3-D model had an effective dynamic gap between the bucket cups and boot wall of $14.48 \mathrm{~mm}$, with the slide gate $2 / 5$ open (i.e., $50.8 \mathrm{~mm}$ ), and the filling time for the LHS hopper to accumulate clear soybeans was $15 \mathrm{~s}$.

- Comparison of predicted average commingling of five quasi-2-D boot models with reduced control volumes showed that the quasi-2-D (5.6d) model provided the best option in reducing computational time; it reduced computational time by $72 \%$ to $74 \%$ compared to the 3-D model.
- Refinement of the quasi-2-D (5.6d) model by accounting for the sudden surge of particles during entry and correcting for the effective dynamic gap between the bucket cups and the boot wall predicted commingling better than the models without those refinements included.

This study showed that grain commingling in a bucket elevator boot system can be simulated in 3-D and quasi-2D DEM models, giving results that agreed with experimental data. The results of this study can be used to predict commingling levels and improve grain handling, which can help farmers and grain handlers reduce costs during transport and export of grains.

\section{ACKNOWLEDGEMENTS}

The research was supported by the USDA-ARS (CRIS No. 5430-43440-007-00D) and by the Kansas Agricultural Experiment Station (Contribution No. 12-254-J). The technical support of Dr. Oleh Baran (formerly with DEM Solutions), Dr. Jasper Tallada (formerly with USDA-ARS CGAHR), Stephen Cole (DEM Solutions), Mark Cook (DEM Solutions), Dr. Sam Wai Wong (formerly with DEM Solutions), and Dr. David Curry (DEM Solutions) and the assistance provided by Mr. Dennis Tilley (USDA-ARS CGAHR) in conducting the experiments are highly appreciated. We also want to thank Dr. Bill Schapaugh (KSU), Vernon Schaffer (KSU), Shaun Winnie (KSU), and Dustin Miller (Kaufmann Seeds) for the fanning mill and soybean samples.

\section{REFERENCES}

Baumeister, T., E. A. Avallone, and T. Baumeister III. 1978. Marks' Standard Handbook for Mechanical Engineers. 8th ed. New York, N.Y.: McGraw-Hill. 
Boac, J. M., M. E. Casada, R. G. Maghirang, and J. P. Harner III. 2010. Material and interaction properties of selected grains and oilseeds for modeling discrete particles. Trans. ASABE 53(4): 1201-1216.

Boresi, A. P., and R. J. Schmidt. 2003. Advanced Mechanics of Materials. 6th ed. New York, N.Y.: John Wiley and Sons.

Bucchini, L., and L. R. Goldman. 2002. Starlink corn: A risk analysis. Environ. Health Perspectives 110(1): 5-12.

Ciesielski, A. 1999. An Introduction to Rubber Technology. Shrewsbury, U.K.: Rapra Technology, Ltd.

Cundall, P. A. 1971. A computer model for simulating progressive large-scale movements in blocky rock systems. In Proc. Symp. Intl. Society of Rock Mechanics, 132-150. Vol. 1, Paper No. II-8. Nancy, France: International Society of Rock Mechanics.

Cundall, P. A., and O. D. L. Strack. 1979. A discrete numerical model for granular assemblies. Geotechnique 29(1): 47-65.

DEM Solutions. 2010. EDEM 2.3 User Guide. Hanover, N.H.: DEM Solutions (USA), Inc.

Di Renzo, A., and F. P. Di Maio. 2004. Comparison of contact-force models for the simulation of collisions in DEM-based granular flow codes. Chem. Eng. Sci. 59(3): 525-541.

Di Renzo, A., and F. P. Di Maio. 2005. An improved integral nonlinear model for the contact of particles in distinct element simulations. Chem. Eng. Sci. 60(5): 1303-1312.

Fazekas, S., J. Kertesz, and D. E. Wolf. 2005. Piling and avalanches of magnetized particles. Physical Review E 71(6): 06130310613039.

Fillot, N., I. Iordanoff, and Y. Berthier. 2004. A granular dynamic model for the degradation of material. J. Tribology 126(3): 606614.

Goda, T. J., and F. Ebert. 2005. Three-dimensional discrete element simulations in hoppers and silos. Powder Tech. 158(1-3): 58-68.

Greenlees, W. J., and S. C. Shouse. 2000. Estimating grain contamination from a combine. ASAE Paper No. MC00103. St. Joseph, Mich.: ASAE.

Hanna, H. M., D. H. Jarboe, and G. R. Quick. 2006. Grain residuals and time requirements for combine cleaning. ASABE Paper No. 066082. St. Joseph, Mich.: ASABE.

Hart, R., P. A. Cundall, and J. Lemos. 1988. Formulation of a threedimensional distinct element method: Part II. Mechanical calculations for motion and interaction of a system composed of many polyhedral blocks. Intl. J. Rock Mech. and Mining Sci. and Geomech. Abstracts 25(3): 117-125.

Hirai, Y., M. D. Schrock, D. L. Oard, and T. J. Herrman. 2006. Delivery system of tracing caplets for wheat grain traceability. Applied Eng. in Agric. 22(5): 747-750.

Ingles, M. E. A., M. E. Casada, and R. G. Maghirang. 2003. Handling effects on commingling and residual grain in an elevator. Trans. ASAE 46(6): 1625-1631.

Ingles, M. E. A., M. E. Casada, R. G. Maghirang, T. J. Herrman, and J. P. Harner III. 2006. Effects of grain-receiving system on commingling in a country elevator. Applied Eng. in Agric. 22(5): 713721.

Joseph, G. G., E. Geffroy, B. Mena, O. R. Walton, and R. R. Huilgol. 2000. Simulation of filling and emptying in a hexagonal-shape solar grain silo. Particulate Sci. and Tech. 18(4): 309-327.

Kamrin, K., C. H. Rycroft, and M. Z. Bazant. 2007. The stochastic flow rule: A multi-scale model for granular plasticity. Modelling and Simulation in Materials Sci. and Eng. 15(4): 449-464.

Kawaguchi, T., M. Sakamoto, T. Tanaka, and Y. Tsuji. 2000. Quasithree-dimensional numerical simulation of spouted beds in cylinder. Powder Tech. 109(1-3): 3-12.

Ketterhagen, W. R., J. S. Curtis, C. R. Wassgren, and B. C. Hancock. 2008. Modeling granular segregation in flow from quasi-threedimensional, wedge-shaped hoppers. Powder Tech. 179(3): 126143.
Kilman, S., and J. Carroll. 2002. Monsanto says crops may contain genetically modified canola seed. The Wall Street Journal. (April 15). Available at: www.connectotel.com/gmfood/monsanto.html. Accessed 15 May 2008.

Li, Y., Y. Xu, and C. Thornton. 2005. A comparison of discrete element simulations and experiments for "sandpiles" composed of spherical particles. Powder Tech. 160(3): 219-228.

Masson, S., and J. Martinez. 2000. Effect of particle mechanical properties on silo flow and stresses from distinct element simulations. Powder Tech. 109(1-3): 164-178.

Miller, G. F., and H. Pursey. 1955. On the partition of energy between elastic waves in a semi-infinite solid. Proc. Royal Soc. London Series $A$ 233(1192): 55-69.

Mindlin, R. 1949. Compliance of elastic bodies in contact. J. Applied Mech. 16(3): 259-268.

Mindlin, R. D., and H. Deresiewicz. 1953. Elastic spheres in contact under varying oblique forces. J. Applied Mech. 20(5): 327-344.

Raji, A. O., and J. F. Favier. 2004a. Model for the deformation in agricultural and food particulate materials under bulk compressive loading using discrete element method: I. Theory, model development, and validation. J. Food Eng. 64(3): 359-371.

Raji, A. O., and J. F. Favier. 2004b. Model for the deformation in agricultural and food particulate materials under bulk compressive loading using discrete element method: II. Compression of oilseeds. J. Food Eng. 64(3): 373-380.

Remy, B., J. G. Khinast, and B. J. Glasser. 2009. Discrete element simulation of free-flowing grains in a four-bladed mixer. AIChE J 55(8): 2035-2048.

Samadani, A., and A. Kudrolli. 2001. Angle of repose and segregation in cohesive granular matter. Physical Review E 64(5): 513011513019.

Shimizu, Y., and P. A. Cundall. 2001. Three-dimensional DEM simulations of bulk handling by screw conveyors. J. Eng. Mech. 127(9): 864-872.

Sudah, O. S., P. E. Arratia, A. Alexander, and F. J. Muzzio. 2005. Simulation and experiments of mixing and segregation in a tote blender. J. American Inst. Chem. Eng. 51(3): 836-844.

Sykut, J., M. Molenda, and J. Horabik. 2008. DEM simulation of the packing structure and wall load in a 2-dimensional silo. Granular Matter 10(4): 273-278.

Takeuchi, S., S. Wang, and M. Rhodes. 2008. Discrete element method simulation of three-dimensional conical-based spouted beds. Powder Tech. 184(2): 141-150.

Theuerkauf, J., S. Dhodapkar, and K. Jacob. 2007. Modeling granular flow using discrete element method: From theory to practice. Chem. Eng. 114(4): 39-46.

Tsuji, Y., T. Tanaka, and T. Ishida. 1992. Lagrangian numerical simulation of plug flow of cohesionless particles in a horizontal pipe. Powder Tech. 71(3): 239-250.

USFDA. 2006. Strategic partnership program agroterrorism (SPPA) initiative: First year status report, September 2005 - June 2006. Silver Spring, Md.: U.S. Food and Drug Administration. Available at: www.fda.gov/Food/FoodDefense/FoodDefensePrograms/ ucm080932.htm. Accessed 15 May 2007.

USDA. 1995. Grain Inspection Handbook: Book I. Grain Sampling. Washington, D.C.: USDA Grain Inspection, Packers, and Stockyards Administration, Federal Grain Inspection Service.

USDA. 2004. Grain Inspection Handbook: Book II. Grain Grading Procedures. Washington, D.C.: USDA Grain Inspection, Packers, and Stockyards Administration, Federal Grain Inspection Service.

Wightman, C., M. Moakher, F. J. Muzzio, and O. R. Walton. 1998. Simulation of flow and mixing of particles in a rotating and rocking cylinder. J. American Inst. Chem. Eng. 44(6): 1266-1276.

Zhou, Y. C., B. H. Xu, A. B. Yu, and P. Zulli. 2001. Numerical investigation of the angle of repose of monosized spheres. Physical Review E 64(2): 0213011-0213018. 